\title{
A revision of the Thyropygus allevatus group. Part V: Nine new species of the extended opinatus subgroup, based on morphological and DNA sequence data (Diplopoda: Spirostreptida: Harpagophoridae)
}

\author{
Piyatida PIMVICHAI ${ }^{1, *}$, Henrik ENGHOFF ${ }^{2}$, Somsak PANHA $^{3} \&$ Thierry BACKELJAU ${ }^{4}$ \\ ${ }^{1}$ Department of Biology, Faculty of Science, Mahasarakham University, \\ Kantharawichai District, Maha Sarakham 44150, Thailand. \\ ${ }^{2}$ Natural History Museum of Denmark, University of Copenhagen, \\ Universitetsparken 15, DK-2100 Copenhagen Ø, Denmark. \\ ${ }^{3}$ Animal Systematics Research Unit, Department of Biology, Faculty of Science, \\ Chulalongkorn University, Bangkok 10330, Thailand. \\ ${ }^{4}$ University of Antwerp, Evolutionary Ecology Group, Groenenborgerlaan 171, \\ B-2020 Antwerp, Belgium and Royal Belgian Institute of Natural Sciences, \\ OD Taxonomy and Phylogeny, and JEMU, Vautierstraat 29, B-1000 Brussels, Belgium. \\ *Corresponding author: piyatida_pimvichai@yahoo.com \\ 2 Email: henghoff@snm.ku.dk \\ ${ }^{3}$ Email: somsakp@sc.chula.ac.th \\ ${ }^{4}$ Email: Thierry.Backeljau@naturalsciences.be \\ ${ }^{1}$ urn:1sid:zoobank.org:author:4D882A89-E0C1-4F78-93E7-FA1B5A2650F2 \\ 2 urn:lsid:zoobank.org:author:FB09A817-000D-43C3-BCC4-2BC1E5373635 \\ ${ }^{3}$ urn:lsid:zoobank.org:author:AC935098-D901-4F35-A414-4B0D4FE44E79 \\ ${ }^{4}$ urn:Isid:zoobank.org:author:E6F42575-36AE-4AD7-98C6-D083EF052568
}

\begin{abstract}
The Thyropygus opinatus subgroup (Diplopoda: Harpagophoridae) of the T. allevatus group in Thailand is revised. Based on a phylogenetic analysis of mtDNA sequence data, it is merged with the $T$. bifurcus subgroup to form an extended T. opinatus subgroup. Nine new species are described: Thyropygus cimi sp. nov. and T. forceps sp. nov. from Nakhonsrithammarat Province, T. culter sp. nov., T. planispina sp. nov., T. undulatus sp. nov. and T. ursus sp. nov. from Krabi Province, T. mesocristatus sp. nov. from Songkhla Province, T. navychula sp. nov. from Phang-Nga Province and T. sutchariti sp. nov. from Phetchaburi Province.
\end{abstract}

Keywords. Millipedes, DNA barcoding, phylogeny, new species, Thailand.

Pimvichai P., Enghoff H., Panha S. \& Backeljau T. 2016. A revision of the Thyropygus allevatus group. Part V: Nine new species of the extended opinatus subgroup, based on morphological and DNA sequence data (Diplopoda: Spirostreptida: Harpagophoridae). European Journal of Taxonomy 199: 1-37. http://dx.doi.org/10.5852/ ejt.2016.199 


\section{Introduction}

The millipede genus Thyropygus Pocock, 1894, is the most species-rich genus of the family Harpagophoridae (subfamily Harpagophorinae) in Southeast Asia. Currently, it includes 56 named species of which 35 occur in Thailand (Enghoff 2005; Jeekel 2006; Pimvichai et al. 2009a, b; 2011a, b). The genus is widely distributed in Southeast Asia and is particularly diverse in Thailand. In a series of previous papers four subgroups of the large Thyropygus allevatus group were revised: the T. opinatus subgroup (Pimvichai et al. 2009a), the T. bifurcus subgroup (Pimvichai et al. 2009b), the T. induratus subgroup (Pimvichai et al. 2011a), and the T. cuisinieri subgroup (Pimvichai et al. 2011b). Yet, several species of the T. allevatus group still have not been assigned to a subgroup.

Although the four currently recognized subgroups of the T. allevatus group appear morphologically distinct, Pimvichai et al. (2014) observed that the T. opinatus and T. bifurcus subgroups did not form separate clades in a mtDNA phylogeny, but instead formed a single mixed clade. This suggested that the two subgroups should not be kept separate, which would also better reflect their morphological similarity (Pimvichai et al. 2009b).

The mitochondrial cytochrome c oxidase subunit I (COI) is widely used for DNA-based species identification (DNA barcoding) of closely related species (Hebert et al. 2003), while mitochondrial 16S rRNA sequences are often used as an additional marker in diplopod taxonomy and phylogeny (Pimvichai et al. 2014). Hence, in the present study, COI and 16S rRNA sequence data are used to (1) delimit species of the T. opinatus and T. bifurcus subgroups, and (2) assess the monophyly of both these subgroups. As a result we describe nine new species and suggest to abandon the concept of a separate T. bifurcus subgroup. Instead, we propose to merge the T. bifurcus and T. opinatus subgroups into an extended T. opinatus subgroup.

\section{Material and methods}

Fresh specimens were hand-collected and preserved partly in $70 \%$ ethanol, partly in a freezer at $-20{ }^{\circ} \mathrm{C}$ for subsequent DNA studies. Specimens were examined from the following collections:

CUMZ = Museum of Zoology, Chulalongkorn University, Bangkok, Thailand

NHMW = Naturhistorisches Museum, Vienna, Austria

ZMUC = Zoological Museum, Natural History Museum of Denmark, University of Copenhagen

Partial COI and 16S rRNA gene sequences were used to construct a phylogenetic tree of Thyropygus species. COI was also used to evaluate genetic divergences between species. The DNA sequence data were extracted from Pimvichai et al. (2014) and supplemented with sequences of seven new samples. The procedures for extracting and analyzing COI and 16S rRNA sequences followed Pimvichai et al. (2014). The COI fragment was amplified using the primers LCO-1490 and HCO-2198 (Folmer et al. 1994), while the 16S rRNA DNA fragment was amplified with the universal primers 16Sar and 16Sbr (Kessing et al. 1989). The new sequences are deposited in GenBank under the accession numbers KU306518-KU306531. Collection localities and accession codes for each nominal species are shown in Table 1.

The COI and 16S rRNA data involve 33 specimens, representing 29 named species. The genus Anurostreptus Attems, 1914 belongs to another harpagophorid subfamily (Rhynchoproctinae), and therefore Anurostreptus barthelemyae Demange, 1961, and A. sculptus Demange, 1961 were used as outgroup taxa. 


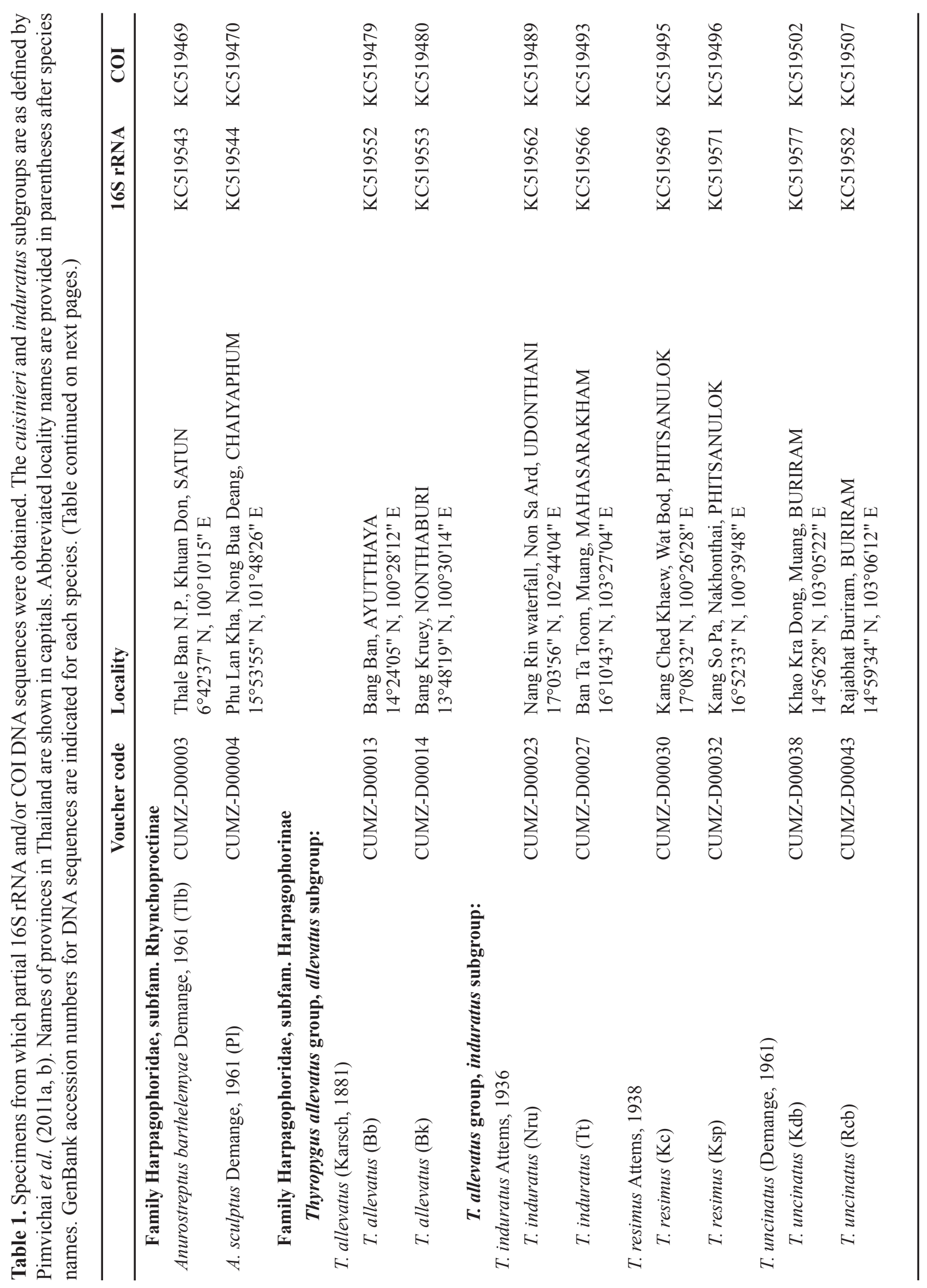




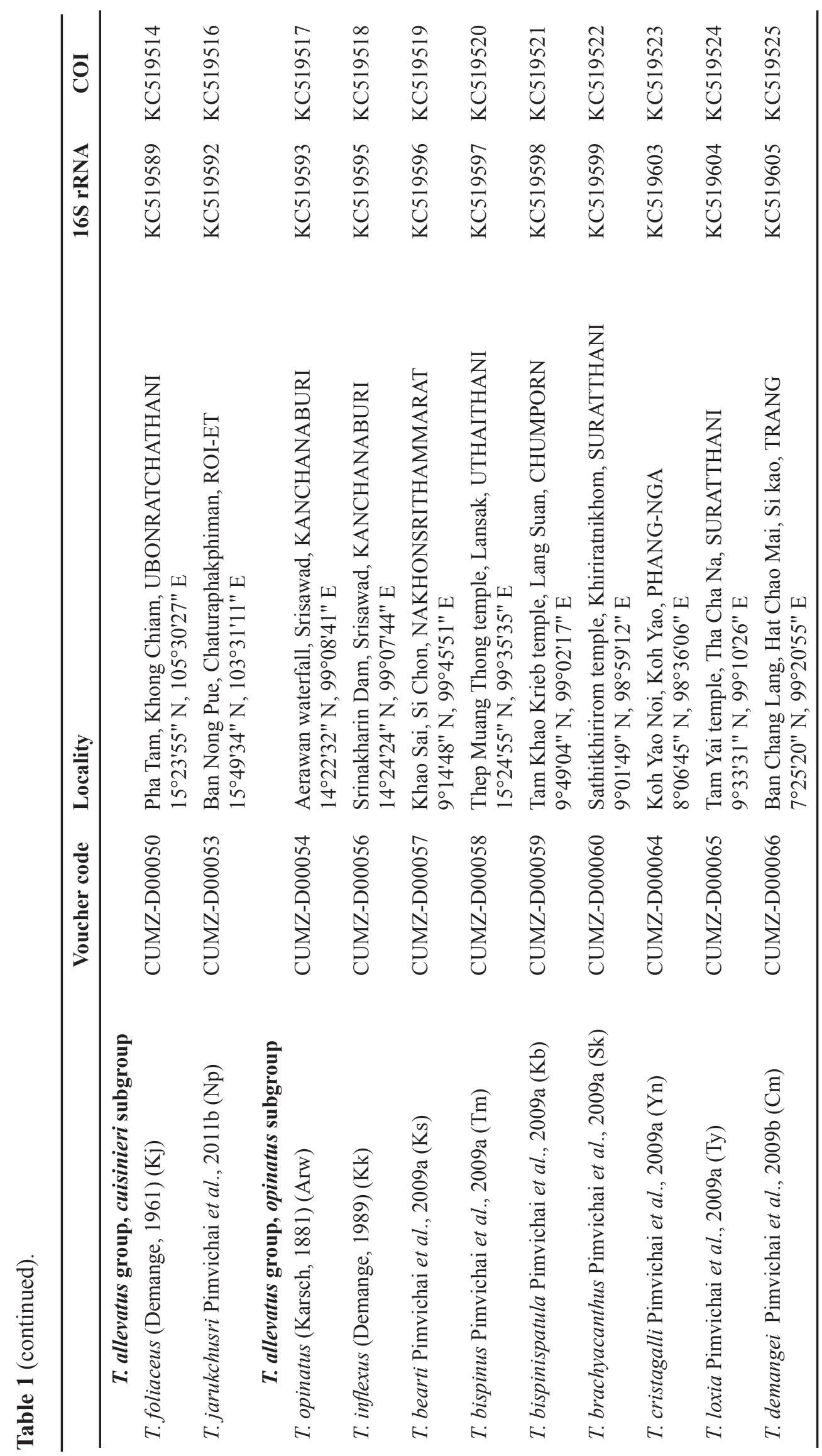




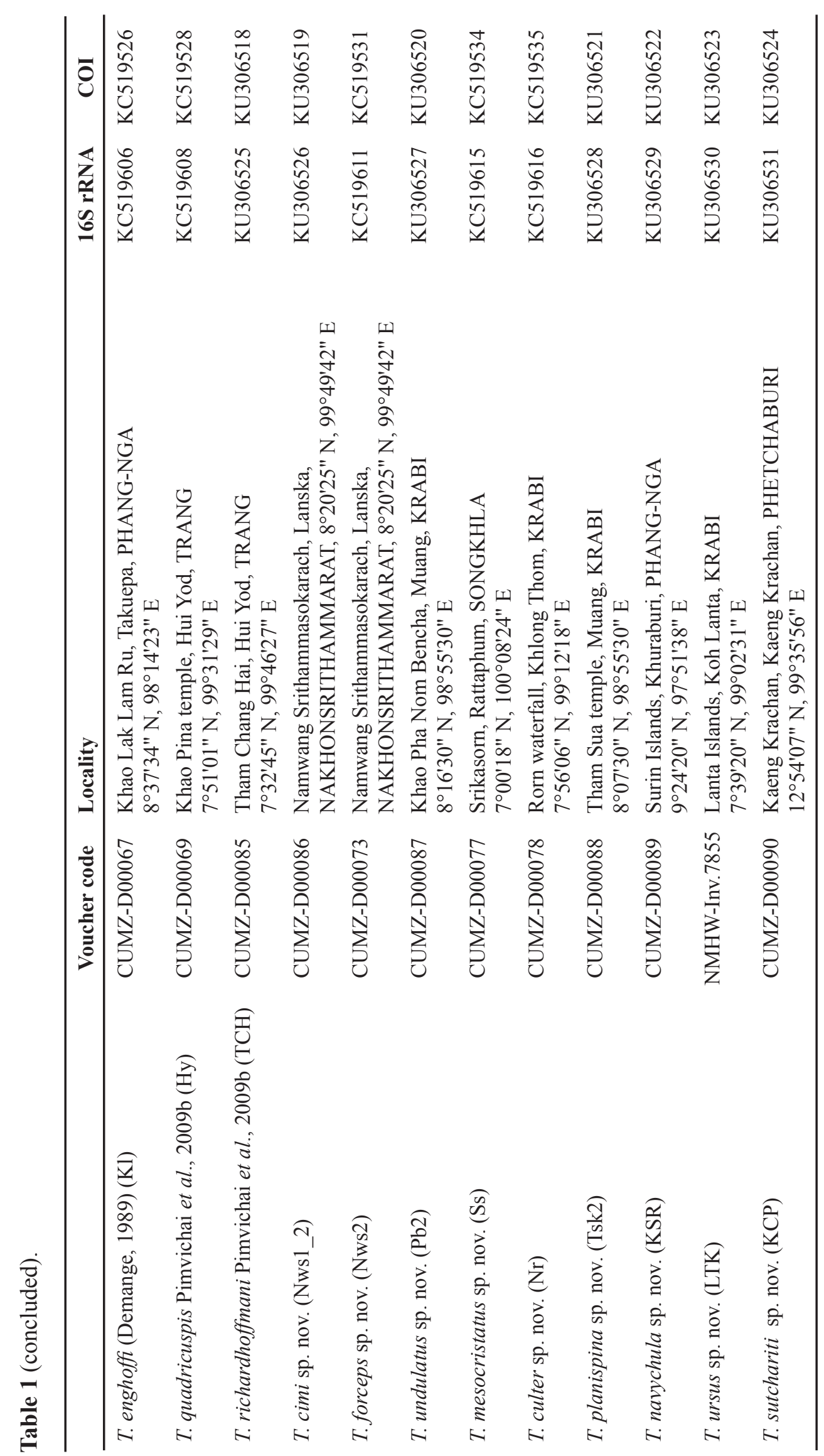




\section{Alignment and phylogenetic analysis}

The resulting forward and reverse sequences were assembled using CodonCode Aligner version 4.0.4 (CodonCode Corporation) and checked for errors/ambiguities. The partial nucleotide sequences (COI, 16S rRNA) were analyzed with the Basic Local Alignment Search Tool (BLAST) provided by NCBI to compare them with known reference sequences in GenBank. DNA sequences were aligned using MUSCLE (Edgar 2004). The two original mtDNA alignments consisted of $660 \mathrm{bp}$ (COI) and $514 \mathrm{bp}$ (16S rRNA). Yet, $27 \mathrm{bp}$, including all the gaps, were excluded from the 16S rRNA because of alignment ambiguities, resulting in a final 16S rRNA alignment of $487 \mathrm{bp}$. The sequences were checked for ambiguous nucleotide sites, saturation and phylogenetic signal using DAMBE version 5.2.65 (Xia 2013). MEGA version 6 (Tamura et al. 2013) was used to (1) perform Tajima's D test for selective neutrality of mutations (D-test statistic), (2) calculate uncorrected pairwise p-distances among sequences, (3) translate COI protein coding sequences into amino acids, (4) check for stop codons, and (5) evaluate transition/transversion rates for COI. Substitution models were inferred independently for each of the gene partitions using jModelTest version 2.1.7 (Darriba et al. 2012) applying Akaike (1974) weights as selection criterion.

Phylogenetic trees were constructed using maximum likelihood (ML) and Bayesian inference (BI). The shape parameter of the gamma distribution, based on 16 rate categories, was estimated using likelihood analysis. ML trees were inferred with RAxML version 8.0.0 (Stamatakis 2014) through the CIPRES Science Gateway (Miller et al. 2010) using a GTR + G substitution model and 1000 bootstrap replicates to assess branch support. The concatenated sequence alignment was partitioned by gene, allowing different evolution rates for COI and 16S rRNA.

The BI analysis was run for 5 million generations (heating parameter $=0.08$ ), sampling every 1000 generations. Convergence was confirmed by verifying that the standard deviations of split frequencies were below 0.01 . Then the first 2500 trees were discarded as burn-in, so that the final consensus tree was built using the last 7502 trees. The optimal parameters were assessed by calculating the Bayes factor using Tracer version 1.6.0 (Rambaut et al. 2014). Support for nodes was defined as posterior probabilities.

\section{Species descriptions}

Drawings were made using a stereo microscope. We have mainly focused on adult males, although adult females and a few juveniles were also available. For the gonopods we used the terminology of Pimvichai et al. (2009a: 21, figs 1-3) with the following abbreviations (terms not used in Pimvichai et al. 2009a, $\mathrm{b}$ in bold):

$a c$ = anterior coxal fold: the main part of gonopod in anterior view; confusingly called posterior coxal fold by Demange (1961) and Hoffman (1975)

aip = additional spine-like process: between lateral and mesal processes of anterior coxal fold

$a l p=$ lateral process of anterior coxal fold: the distolateral part of the anterior coxal fold

$a m p=$ mesal process of anterior coxal fold: an additional projection on the anterior coxal fold, protruding from its mesal margin

$b p=$ blepharochaete (pl. -ae): the normal form of apical setae, long, slender, stiffened, and usually pigmented, somewhat reminiscent of the mammalian eyelash (Hoffman 1975)

cr = longitudinal crest in gutter of palette: a crest which runs along the middle of the gutter near the tip of the palette

$f e=$ femoral spine (also $f e l$ and $f e$ 2): a usually long, curved spine on the telopodite, originating slightly distal to the point where the telopodite emerges from the coxa

$\boldsymbol{l c}=$ longitudinal crest: a strong longitudinal crest at the mesal margin of amp in posterior view

$l l=$ lamellar lobe: a small, slightly folded lobe at the basis of the apical part of the telopodite

$p a=$ palette: the distalmost lobe of the apical part, carrying the row of blepharochaetae 
$p c=$ posterior coxal fold: the main part of gonopod in posterior view, usually shorter than $a c$ and forming shelf for accommodation of telopodite shaft

$p l p=$ lateral process of posterior coxal fold: the lateral part of the posterior coxal fold, normally digitiform

$p m p=$ mesal process of posterior coxal fold: the mesal part of the posterior coxal fold, normally forming a shelf for accommodation of telopodite shaft

$p x=$ paracoxite: the basal, lateral part of the posterior coxal fold

$s l=$ spatulate lobe: a distinct distal, separate lobe at the apical part, spatulate, sometimes with a distal spine-like process

$s l s=$ slender long spine: an additional slender long spine (much longer than ss) at the base of the apical part of telopodite in posterior view

$s s=$ small spine: an additional small spine at the base of the apical part of telopodite in posterior view

st = sternum: a small, usually triangular sclerite between the basal parts of the anterior coxal folds

$t i=$ tibial spine: a usually long spine on the telopodite, originating distal to the femoral spine, at the basis of the apical part of the telopodite, usually curved in the opposite direction of the femoral spine, the two together forming a circle

Apical part: the part of the telopodite distal to the tibial spine

Shelf: the distal surface of the posterior coxal fold

\section{Results}

\section{DNA sequence data}

The COI dataset included $660 \mathrm{bp}$, while the 16S rRNA dataset included $487 \mathrm{bp}$. The concatenated dataset therefore comprised $1147 \mathrm{bp}$.

The aligned COI gene fragment (660 bp) had nucleotide frequencies of $0.287,0.226,0.161$ and 0.326 for A, C, G and T, respectively, (37.8\% GC content). The uncorrected p-distance between the taxa ranged from 0.02 to 0.21 (Table 2).

The aligned 16S rRNA gene fragment (487 bp), had nucleotide frequencies of $0.324,0.100,0.210$ and 0.366 for A, C, G and T, respectively ( $29.9 \%$ GC content). The uncorrected p-distance between the taxa ranged from 0.00 to 0.15 (Appendix I).

The concatenated data set (1147 bp) had nucleotide frequencies of $0.303,0.172,0.182$ and 0.343 for A, C, G and T, respectively ( $35.3 \%$ GC content). The uncorrected p-distance between the taxa ranged from 0.01 to 0.18 . The estimated value of the shape parameter, as evaluated by MEGA version 6 with the substitution pattern and rates fitted by the GTR $+\mathrm{G}$ model (Kumar \& Nei 2000), for the discrete Gamma Distributions (Gu et al. 1995) were 0.1542, 0.1584 and 0.1424 for the COI fragment, 16S rRNA (unambiguously aligned sequences) and the concatenated data set, respectively.

D values for selective neutrality were 1.91, 0.63 and 1.45 for COI, $16 \mathrm{~S}$ and the combined sequences, respectively. The COI transition/transversion ratio was 2.24 .

\section{Phylogeny}

For ML analyses, we consider clades with bootstrap values of $70 \%$ and above to be well-supported (Hillis \& Bull 1993), and below as not significantly supported; thus, we refer to clades with bootstrap values between $70 \%$ and $79 \%$ as moderately supported, between $80 \%$ and $89 \%$ as strongly supported, and $90 \%$ and above as very strongly supported. For BI analyses, we regard clades with posterior probabilities of 0.95 and above to be strongly supported and below as not significantly supported. 


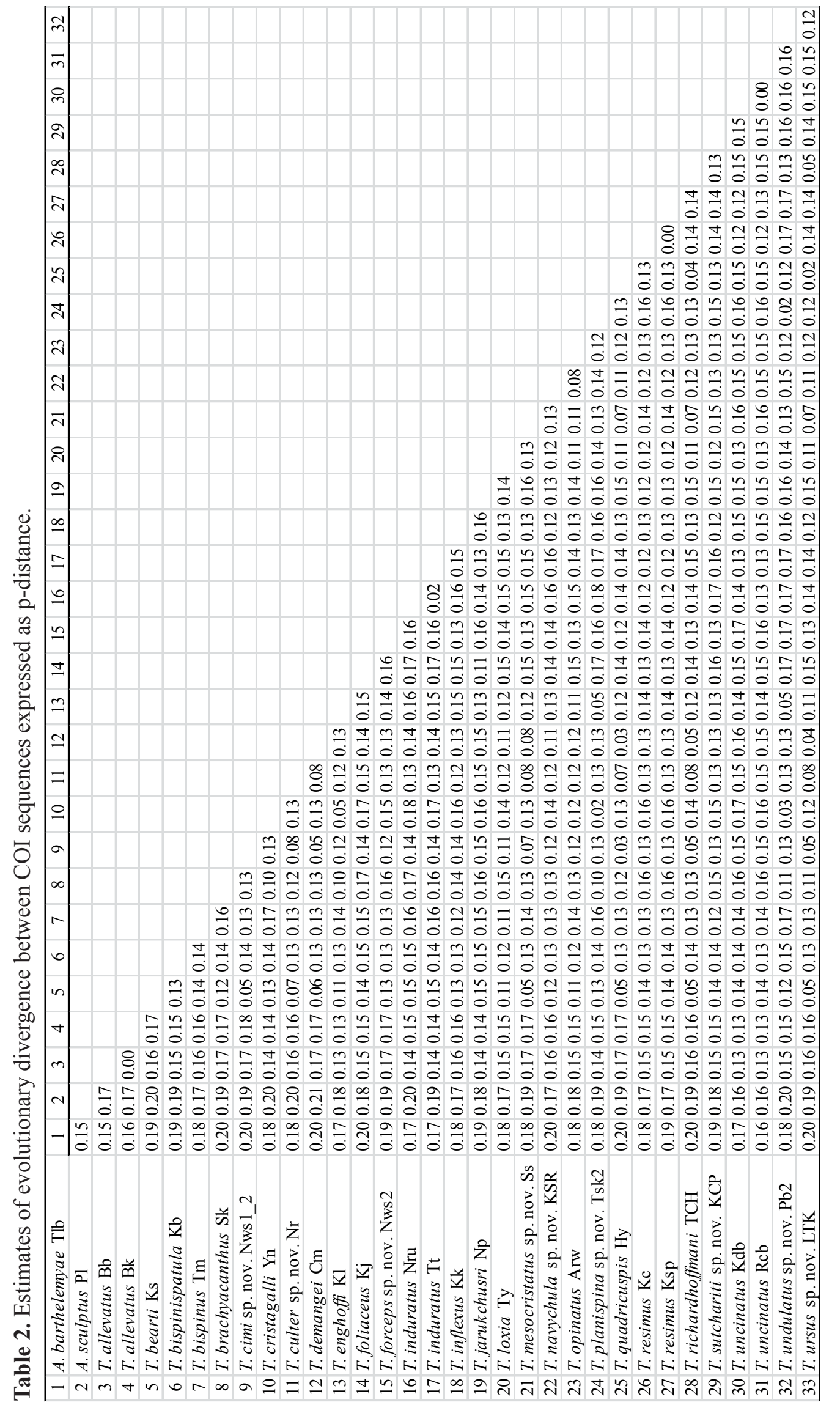


The ML and BI phylogenetic trees reconstructed by separate and combined analyses of the partial COI and 16S rRNA were largely congruent (by visual inspection of the branch pattern). Indeed, the COI and concatenated COI+16S rRNA trees were topologically identical, whereas the $16 \mathrm{~S}$ rRNA tree only showed topological differences for unresolved or unsupported nodes. The single gene trees (COI and 16S rRNA) are presented in Appendices II and III. Thus, we have selected the combined COI plus 16S rRNA phylogeny derived from the ML analysis for further discussion (Fig. 1). The best-fit substitution models for the ML tree under the Akaike information criterion (Akaike 1974) was the TIM1 + I + G $(-\operatorname{lnL}=5531.3288$, gamma shape $=0.7890)$ and TIM3 $+\mathrm{I}+\mathrm{G}(-\operatorname{lnL}=2557.2902$, gamma shape $=0.4540)$ model for COI and 16S rRNA, respectively. The Thyropygus clade (Clade 1, 27 included species) is strongly supported by $100 \%$ for ML bootstrap replicates, and a BI posterior probability of 1.00 .

Clade 1A1, Thyropygus allevatus is very strongly supported (100\% for ML bootstrap replicates and a BI posterior probability of 1.00).

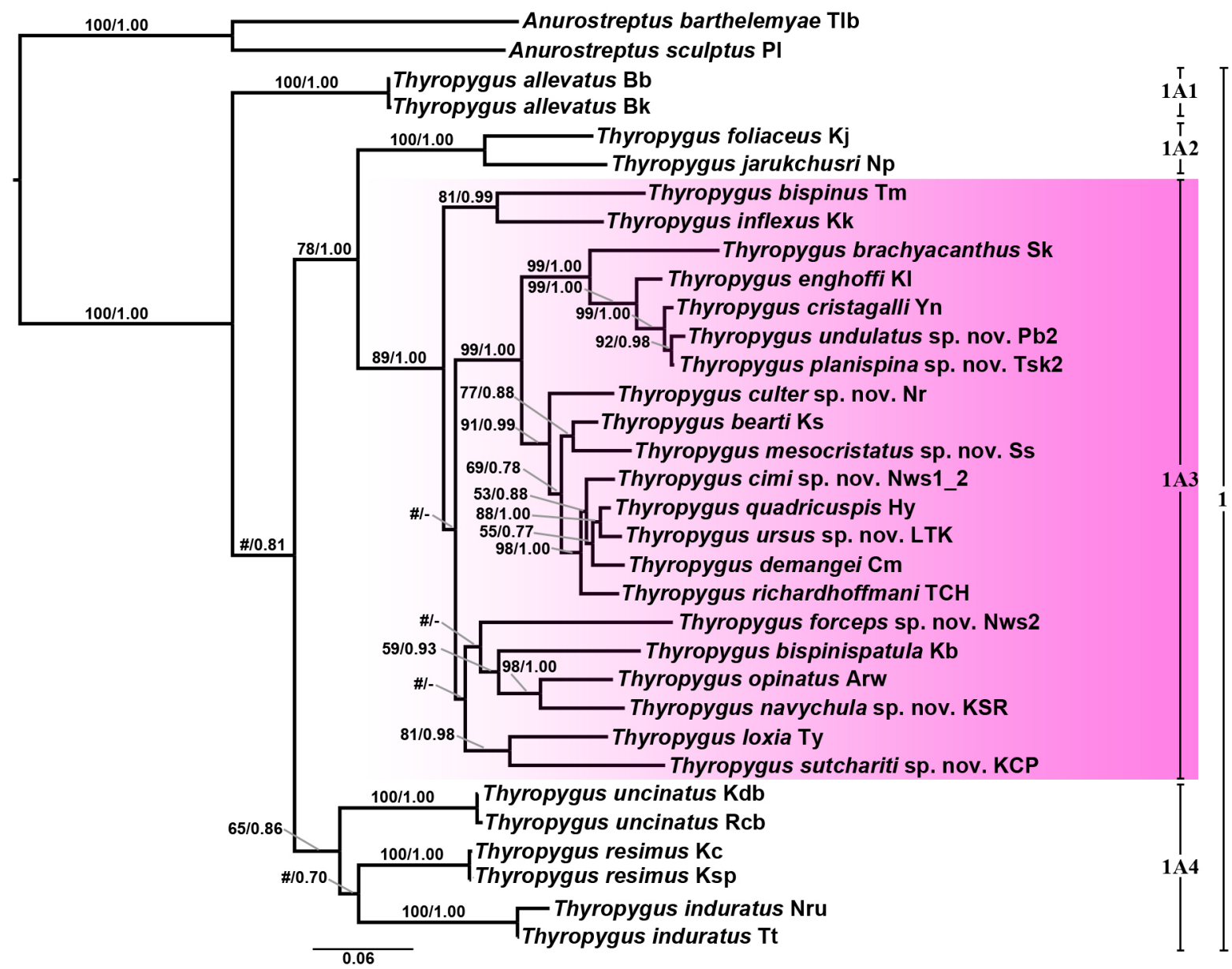

Fig. 1. Phylogenetic relationships of Thyropygus species based on maximum likelihood analysis (ML) and Bayesian Inference (BI) of $1147 \mathrm{bp}$ of concatenated gene fragments of COI (660 bp) and 16S rRNA (487 bp). Numbers at nodes indicate branch support based on bootstrapping (ML) / posterior probability (BI). Scale bar $=0.06$ substitutions/site. \# indicates branches which received $<50 \% \mathrm{ML}$ bootstrap support, - indicates non-supported branches by posterior probability. Clade memberships and designations are shown as vertical bars; $1 \mathrm{~A} 1=$ T. allevatus, $1 \mathrm{~A} 2=$ cuisinieri subgroup, $1 \mathrm{~A} 3=$ opinatus subgroup and $1 \mathrm{~A} 4=$ induratus subgroup. The coloured area marks the T. opinatus subgroup. Abbreviations after species names refer to locality names as shown in Table 1. 
Clade 1A2, T. cuisinieri subgroup (here represented by foliaceus and jarukchusri) is very strongly supported ( $100 \%$ for ML bootstrap replicates and a BI posterior probability of 1.00$)$.

Clade 1A3 (coloured highlight), is strongly supported by $89 \%$ ML bootstrap replicates and strongly supported by a BI posterior probability of 1.00 , and is a monophyletic group consisting of a mixture of species from the T. opinatus and T. bifurcus subgroups (Pimvichai et al. 2009a, b), including the nine new species described in this study. Thus, we treat all species of these subgroups as a single subgroup viz., the extended T. opinatus subgroup (henceforward simply "the T. opinatus subgroup").

Clade 1A4, the T. induratus subgroup (induratus, resimus and uncinatus) is not significantly supported ( $65 \%$ for ML bootstrap replicates and a BI posterior probability of 0.86 ).

\section{Taxonomy}

The Thyropygus opinatus subgroup (including the T. bifurcus subgroup of Pimvichai et al. 2009b)

This is a subgroup of the T. allevatus group, characterized by an additional projection on the anterior coxal fold (amp). Included species:

T. bearti Pimvichai et al., 2009a

T. bifurcus (Demange, 1986)

T. bispinispatula Pimvichai et al., 2009a

T. bispinus Pimvichai et al., 2009a

T. brachyacanthus Pimvichai et al., 2009a

T. casjeekeli Pimvichai et al., 2009b

T. chelatus Pimvichai et al., 2009a

T. cristagalli Pimvichai et al., 2009a

T. demangei Pimvichai et al., 2009b

T. enghoffi (Demange, 1989)

T. erectus Pimvichai et al., 2009a

T. floweri (Demange, 1961)

T. implicatus (Demange, 1961)

T. inflexus (Demange, 1989)

T. loxia Pimvichai et al., 2009a

T. opinatus (Karsch, 1881)

T. quadricuspis Pimvichai et al., 2009b

T. richardhoffmani Pimvichai et al., 2009b

T. cimi sp. nov.

T. culter sp. nov.

T. forceps sp. nov.

T. mesocristatus sp. nov.

T. navychula sp. nov.

T. planispina sp. nov.

T. sutchariti sp. nov.

T. undulatus sp. nov.

T. ursus sp. nov.

In addition to the diagnostic character combination given by Pimvichai et al. (2009a, b), all species in the opinatus subgroup share common characters of head, antennae, mandibles, gnathochilarium, collum, epiproct, paraprocts, hypoproct and first pair of male legs. We therefore give a general description of males of the opinatus subgroup, so that subsequent species descriptions (which are mainly based on males) can be kept brief. 


\section{General description of males of the T. opinatus subgroup}

Head smooth, 5-8 supralabral setae, eyes moderate in size, ocelli in 7-8 horizontal rows consisting of 11-14, 10-13, 8-11, 7-9, 5-8, 3-6, 1-4 and 1-3 ocelli, total: 46-68.

Gnathochilarium: mentum smooth, at most with a few small setae distally and a large, horseshoe-shaped ridge opening distally. Stipites densely covered with spine-like setae, except for an irregular oblique band from $c$. middle of lateral margin to border of lamella lingualis; long setae present on the distolateral part; males (not females) distally with a small sclerotised 'island' with 1-3 spine-like setae in middle of an ovoid, poorly sclerotized, hairless area. Lamellae linguales with three long, apical setae and a number of short, basal, spine-like setae.

Sterna smooth, stigmatal grooves distinct, long. Legs relatively long; tip of postfemora, tibiae and tarsi visible from above when legs are extended laterad; coxae of anterior and posterior pair markedly dissimilar, posterior coxae humped; coxae with 2-8 setae, prefemora with 3-6 setae, femora with 2-5 setae in a median row and 2 larger, subapical setae; tarsi typically with 6-8 irregularly placed ventral setae and 1-2 large dorsal, apical spurs. Postfemora and tibiae without setae.

Ventral pads on postfemora and tibiae on all legs, except first three pairs.

Gonopods: sternum (st) triangular. Anterior coxal fold $(a c)$ basally slender, becoming broader towards tip, lateral margins diverging; distally with two processes: a lateral process ( $a l p)$ and a usually smaller mesal process ( $a m p)$; the shape of these processes is species-specific. Posterior coxal $(p c)$ fold much lower than anterior coxal fold, basally with moderately high lateral paracoxites ( $p x)$, distally variously modified but always with a smooth area over which the telopodite shaft can slide. Telopodite with a single or double, well-developed femoral spine $(f e)$ and a long, slender, curved tibial spine ( $t i)$. Many species with a characteristic spatulate lobe $(s l)$ originating under the base of the tibial spine; lobe sometimes distally rounded, spoon-like, sometimes ending in a large, stout spine. Other species instead with a small and slightly folded lateral lamella $(l l)$. Apical palette $(p a)$ simple, forming a broad gutter, sometimes with a longitudinal crest in the concavity; apically with a row of 7-13 brownish blepharochaetae $(b p)$.

Key to species of the T. opinatus subgroup (partly extracted and adapted from Pimvichai et al. 2009a, b)

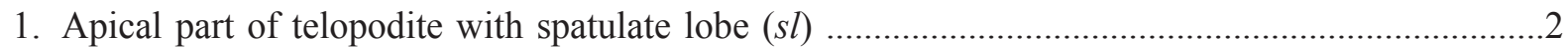

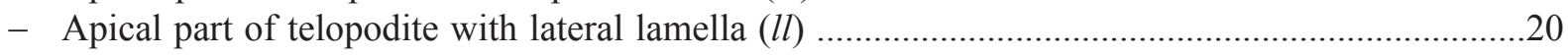

2. Spatulate lobe $(s l)$ distally drawn out into one (rarely two) sharp dark brown spine(s) .............3

- Spatulate lobe $(s l)$ distally expanded and/or rounded, spoon-like, without a spine ....................

3. Spatulate lobe $(s l)$ terminating in two sharp brown spines, the outer spine slightly smaller and shorter than the inner one; lateral process of anterior coxal fold (alp) slender, slightly curving mesad; mesal process of anterior coxal fold (amp) almost as long as alp, flattened

T. bispinispatula Pimvichai et al., 2009a

- Spatulate lobe $(s l)$ terminating in a single sharp dark brown spine

4. Telopodite without a lobe distal to femoral spine ( $f e$ ); lateral process of anterior coxal fold (alp) long, slender, regularly curved, tip close to tip of opposite alp, the two together forming a circle; mesal process of anterior coxal fold ( $a m p$ ) straight, shorter than alp; fe directed distad, pointed

T. erectus Pimvichai et al., 2009a

- Telopodite distally to $f e$ with a large, round lobe $(l o)$, projecting distolaterally ......................5 
5. Lateral process of anterior coxal fold (alp) very slender, regularly curved ..........................6

- Lateral process of anterior coxal fold (alp) different, broader and/or with several apical denticles ...8

6. Mesal margin of lateral process of anterior coxal fold (alp) with fine serrations (Fig. 6A); mesal process of anterior coxal fold ( $\mathrm{amp}$ ) almost as long as alp, broadly expanded, apically sharp, straight distad, mesal margin forming a strong longitudinal crest $(l c)$ in posterior view (Fig. 6B)

..T. navychula sp. nov.

- Mesal margin of lateral process of anterior coxal fold (alp) without serrations, tip of lateral process close to tip of the opposite side, the two together forming a circle

7. Mesal process of posterior coxal fold ( $\mathrm{pmp}$ ) strongly developed along anterior-posterior axis .....

T. floweri (Demange, 1961)

- Mesal process of posterior coxal fold ( $\mathrm{pmp}$ ) slender, directed distolaterad (Fig. 4C)

..T. forceps sp. nov.

8. Lateral process of anterior coxal fold (alp) broad, apically gradually narrowed; mesal process of anterior coxal fold ( $a m p$ ) almost as long as alp, slender, straight, terminally slightly curved, pointed ............................................................................................... opinatus (Karsch, 1881)

- Lateral process of anterior coxal fold (alp) apically bent abruptly mesad, tip with serrate margins; mesal process of anterior coxal fold ( $\mathrm{amp}$ ) much shorter than alp, directed meso-distad, simple, pointed; mesal process of posterior coxal fold ( $\mathrm{pmp}$ ) strongly developed along anteriorposterior axis

T. implicatus (Demange, 1961)

9. Telopodite with a single femoral spine .10

- Telopodite with a double femoral spine 17

10. Lateral process of anterior coxal fold (alp) apically abruptly truncate

T. bearti Pimvichai et al., 2009a

- Lateral process of anterior coxal fold (alp) apically pointed

11. Mesal process of anterior coxal fold ( $\mathrm{amp}$ ) very small; telopodite distally to $f e$ with a small round lobe $(l o)$ projecting distolaterally T. loxia Pimvichai et al., 2009a

- Mesal process of anterior coxal fold ( $\mathrm{amp}$ ) relatively long

12. Mesal process of anterior coxal fold ( $a m p)$ shorter than lateral process (alp) .13

- Mesal process of anterior coxal fold (amp) as long as lateral process (alp)

13. Mesal process of anterior coxal fold ( $\mathrm{amp}$ ) directed obliquely disto-mesad, slender, straight ......

T. chelatus Pimvichai et al., 2009a

- Mesal process of anterior coxal fold ( $\mathrm{amp}$ ) directed distad, thicker, slightly sigmoid

T. brachyacanthus Pimvichai et al., 2009a

14. Mesal process of anterior coxal fold (amp) directed obliquely disto-mesad, tip overlapping tip of opposite amp (Fig. 8A); lateral process of posterior coxal fold ( $p l p)$ a massive, broad lobe, projecting laterad (Fig. 8B)

T. sutchariti sp. nov.

- Mesal process of anterior coxal fold ( $a m p$ ) directed distad

15. Lateral process of anterior coxal fold (alp) apically without a crest; telopodite distally with a rounded lobe $(l o)$; margins of spatulate lobe $(s l)$ terminally meeting in a distinct angle

T. bispinus Pimvichai et al., 2009a

- Lateral process of anterior coxal fold (alp) apically with a crest 
16. Mesal process of anterior coxal fold ( without a rounded lobe $(l o)$

T. inflexus (Demange, 1989)

- Mesal process of anterior coxal fold ( forming a strong longitudinal crest $(l c)$ in posterior view (Fig. 5B)

T. mesocristatus sp. nov.

17. Anterior coxal fold $(a c)$ with an additional spine-like process (aip) between lateral process of anterior coxal fold (alp) and mesal process of anterior coxal fold (amp); alp broad, mesal margin concave, tip with serrate margins, cockscomb-like; amp much shorter than alp, directed meso-distad, simple, pointed; both femoral spines ( $f e$ ) slender, long ............T. cristagalli Pimvichai et al., 2009a

- Anterior coxal fold (ac) without an additional spine-like process (aip) between alp and amp ...18

18. Lateral process of anterior coxal fold ( $a l p$ ) apically without a crest, flattened, slightly curved, its laterodistal margin coarsely dentate, terminating in a short, sharp, pointed spine (Fig. 3A); mesal process ( $(\mathrm{m} p \mathrm{p}$ ) much shorter than alp, directed distad, tip curving mesad, pointed; both femoral spines ( $\mathrm{fe}$ 1, $f e$ 2) long, curving backward; tibial spine (ti) long, not curving in horizontal plane (Fig. 3C)

T. culter sp. nov.

- Lateral process of anterior coxal fold (alp) apically with a crest extending caudad 19

19. Lateral process of anterior coxal fold (alp) flattened, curving mesad, laterodistal margin coarsely dentate, terminating in a short spine, tip curving against the tip of opposite side (Fig. 9A); mesal process of anterior coxal fold ( $a m p)$ much shorter than alp, slender, curving mesad; both femoral spines ( $f e$ l, fe 2) broad, long; tibial spine ( $t i)$ long, curving in horizontal plane, not ending in a sharp spine (Fig. 9D)

T. undulatus sp. nov.

- Lateral process (alp) regularly curved, terminating in a sharp, slightly upward-pointing spine (Fig. 7A); mesal process ( $\mathrm{amp}$ ) slightly shorter than alp, flattend, straight, directed distad; tibial spine ( $t i$ ) flattend, short, curving mesad (Fig. 7D)

T. planispina sp. nov.

20. Telopodite with a single femoral spine

- Telopodite with a double femoral spine

21. Lateral process of anterior coxal fold (alp) without an apical crest; mesal process of anterior coxal fold (amp) shorter than and as broad as alp, directed distad; femoral spine ( $f e$ ) very long and slender

T. casjeekeli Pimvichai et al., 2009b

- Lateral process of anterior coxal fold (alp) with a sharp crest on the posterior surface near the tip ...22

22. Lateral process of anterior coxal fold (alp) flattened, slightly curved, inflexed; femoral spine $(f e)$ very long, slender, with an additional lamella at base ...T. quadricuspis Pimvichai et al., 2009b

- Lateral process of anterior coxal fold (alp) regularly curved, basally broad, gradually tapering towards end and ending in sharp point (Fig. 2A); femoral spine ( $f e$ ) very long, slender, without an additional lamella at base (Fig. 2D) T. cimi sp. nov.

23. Lateral process of anterior coxal fold (alp) broader .24

- Lateral process of anterior coxal fold (alp) slender, regularly curved, sickle-shaped 25

24. Lateral process of anterior coxal fold ( $a l p)$ terminating in a very short external spine and a very long internal one; mesal process of anterior coxal fold ( $\mathrm{amp}$ ) as long as alp; first femoral spine (fe 1 ) very short, pointed; second femoral spine ( $f e$ 2) very long, as long as tibial spine ( $t i)$; an additional lamella at both sides of base of $f e 2$

T. richardhoffmani Pimvichai et al., 2009b

- Lateral process of anterior coxal fold (alp) flattened, apically curved laterad as a short spine, lateral margin of alp slightly folded; mesal process of anterior coxal fold (amp) shorter than alp, slender, straight, directed distad, pointed (Fig. 10A); the first femoral spine (fe l) very 
short, directed upward, situated above the second femoral spine (fe 2); fe 2 very long, slender, curved downward (Fig. 10C) T. ursus sp. nov.

25. Mesal margin of lateral process of anterior coxal fold (alp) simple, without a caudad spine or crest; mesal process of anterior coxal fold ( $a m p$ ) much shorter than alp, curved, pointed .

T. enghoffi (Demange, 1989)

- Mesal margin of lateral process of anterior coxal fold (alp) caudad with a small spine or crest ......26

26. Mesal margin of lateral process of anterior coxal fold (alp) with a small caudad crest; mesal process of anterior coxal fold ( $\mathrm{amp}$ ) slightly shorter than alp, slightly sigmoid, pointed

T. bifurcus (Demange, 1986)

- Mesal margin of lateral process of anterior coxal fold (alp) with a short curved caudad spine; mesal process of anterior coxal fold (amp) as long as alp, straight ...T. demangei Pimvichai et al., 2009b

\section{Species descriptions}

Class Diplopoda Blainville-Gervais, 1844

Order Spirostreptida Brandt, 1833

Family Harpagophoridae Attems, 1909

Subfamily Harpagophorinae Attems, 1909

Thyropygus Pocock, 1894

Thyropygus cimi sp. nov. urn:1sid:zoobank.org:act:0252646C-AD4E-4B8B-8A7C-AEEA80DD4A72

Fig. 2A-E

\section{Diagnosis}

A species of the opinatus subgroup. Lateral process of anterior coxal fold (alp) regularly curved, basally broad, gradually tapering towards end and ending in sharp point, with a lateral crest near tip. Similar in this respect to T. bifurcus. Differs from this species by having the mesal process of anterior coxal fold ( $\mathrm{amp}$ ) straight, directed distad, by having the mesal process of posterior coxal fold ( $\mathrm{pmp}$ ) slender, directed anteriad, and by having only one femoral spine $(f e)$.

\section{Etymology}

This species is named after the organization "Centre International de Myriapodologie - CIM" (www. myriapodology.org) in recognition of its immense importance for inspiring and supporting research on myriapods.

\section{Material examined}

Holotype

THAILAND: $\hat{\delta}$, Nakhonsrithammarat Province, Lanska District, Namwang Srithammasokrach, $8^{\circ} 20^{\prime} 25^{\prime \prime}$ N, 9949'42" E, 16 May 2010, leg. S. Panha, P. Pimvichai and members of the Animal Systematics Research Unit (CUMZ-D00086).

\section{Paratypes}

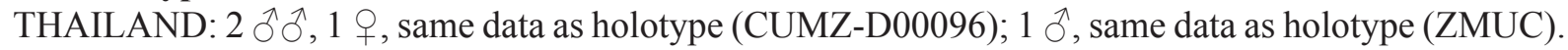

\section{Description}

Adult males with $65-68$ podous rings, no apodous rings. Length $13-16 \mathrm{~cm}$, width $7.6-8.3 \mathrm{~mm}$. Adult female with 65 podous rings, no apodous rings. Length $13 \mathrm{~cm}$, width $7.4 \mathrm{~mm}$. Colour in life unknown; 
preserved specimens with head, antennae, prozona, middorsal metazona and legs brown; metazona, epiproct, paraprocts and hypoproct dark brown.

Gonopods (Fig. 2A-E). Anterior coxal fold (ac; Fig. 2A): lateral process (alp) regularly curved, basally broad, gradually tapering towards end and ending in sharp point, with lateral crest near tip (Fig. $2 \mathrm{C}$, arrow); mesal process ( $a m p$ ) slightly shorter than alp, straight, directed distad. Posterior coxal fold ( $p c$; Fig. 2B) basally with moderately high lateral paracoxites $(p x)$, distally truncate, forming shelf for accommodation of telopodite, mesal process ( $\mathrm{pmp}$ ) slender, directed anteriad. Telopodite (Fig. 2D-E) leaving coxite over shelf of posterior coxal fold; femoral spine $(f e)$ very long, slender, curving downward, in situ resting between alp and $a m p$; tibial spine (ti) long, slender, curving in horizontal plane, its tip

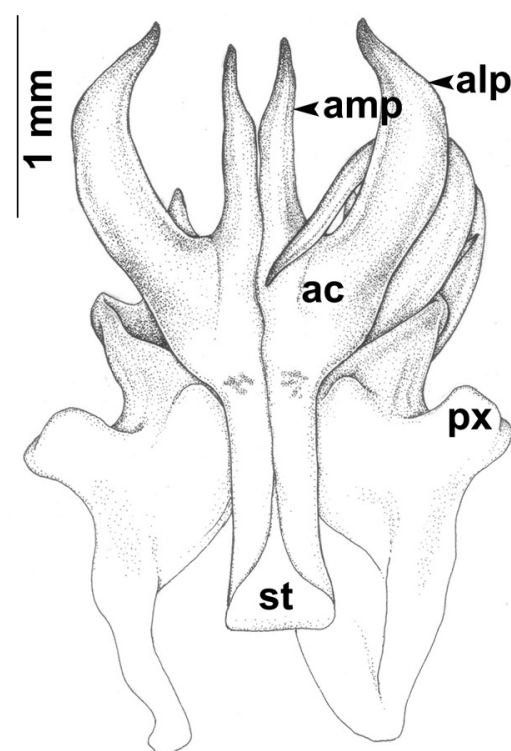

A

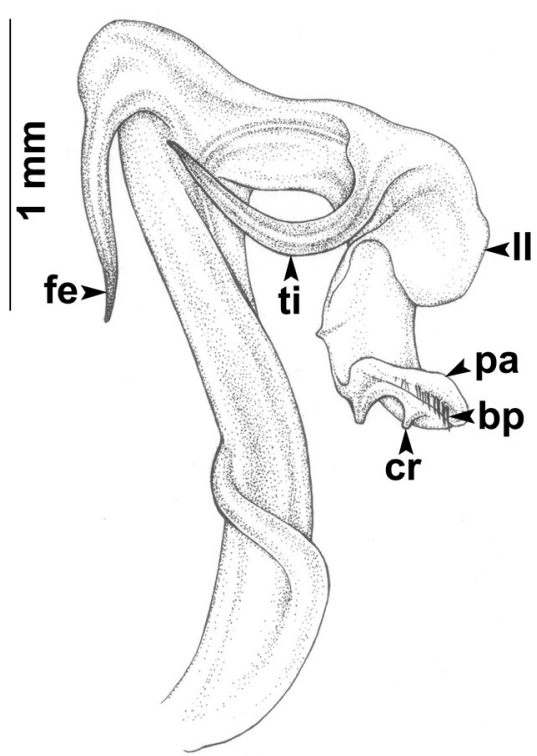

D

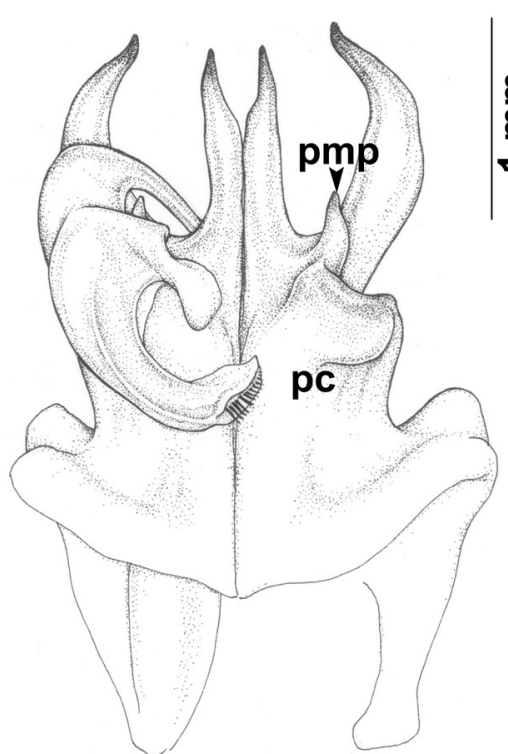

B

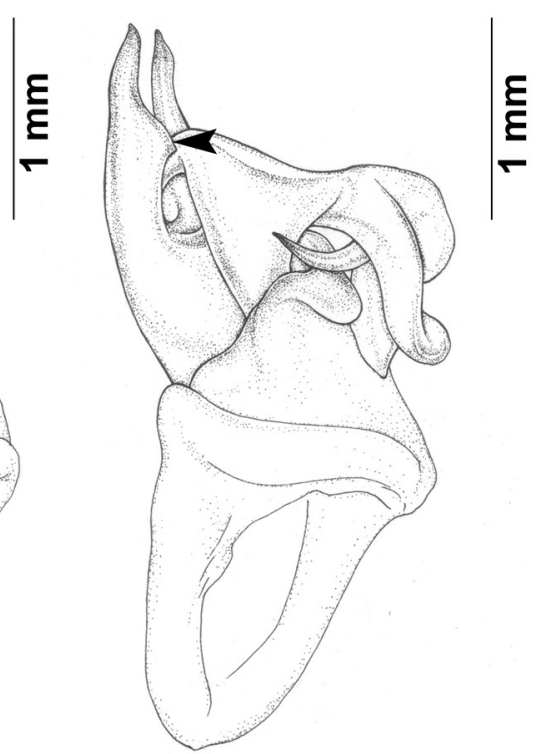

C

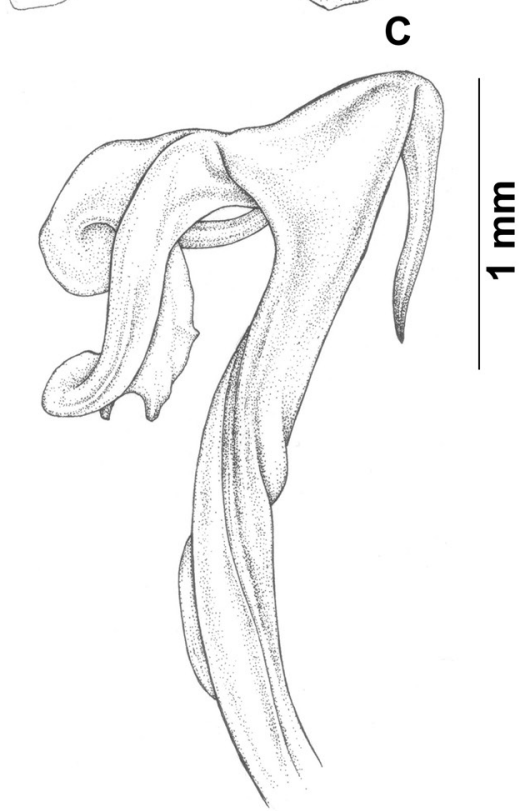

$\mathbf{E}$

Fig. 2. Thyropygus cimi sp. nov., from Namwang Srithammasokrach, holotype (CUMZ-D00086), $\hat{\jmath}$, gonopods. A. Anterior view, left telopodite removed. B. Posterior view, left telopodite removed. C. Lateral view. D. Left telopodite, posterior-mesal view. E. Left telopodite, anterior-lateral view. 
in situ resting close to base of $f e$; apical part: lamellar lobe $(l l)$ broadly expanded, bent down; palette ( $p a$ ) simple, gutter-like, with longitudinal rounded crest ( $c r$ ) at middle; distally with about ten brownish blepharochaetae $(b p)$.

\section{DNA barcode}

The GenBank accession number of the barcode of the holotype is KU306519 (voucher code CUMZ-D00086).

\section{Distribution (Fig. 12)}

Known only from the type locality.

\section{Remarks}

Coexisting with the smaller $T$. forceps sp. nov.

Thyropygus culter sp. nov.

$$
\text { urn:1sid:zoobank.org:act:0093C39D-F1FC-4CAD-9DA0-0492F45E7370 }
$$

Fig. 3A-D

\section{Diagnosis}

A species of the opinatus subgroup. Lateral process of anterior coxal fold (alp) flattened, slightly curved, its laterodistal margin coarsely dentate. Similar in this respect to T. cristagalli, T. implicatus and T. undulatus sp. nov. Differs from these species by having the mesal process of posterior coxal fold $(\mathrm{pmp})$ very high, pointed-triangular, directed almost straightly distad, and by having the tibial spine $(t i)$ recurved.

\section{Etymology}

The name is a Latin noun in apposition, meaning "knife", and refers to the knifelike second femoral spine $(f e$ 2).

\section{Material examined}

\section{Holotype}

THAILAND: ${ }^{\wedge}$, Krabi Province, Khlong Thom District, Rorn waterfall, $7^{\circ} 56^{\prime} 06^{\prime \prime} \mathrm{N}, 9^{\circ} 12^{\prime} 18^{\prime \prime} \mathrm{E}$, 15 Jan. 2009, leg. P. Pimvichai, C. Sutcharit and members of the Animal Systematics Research Unit (CUMZ-D00091).

\section{Paratypes}

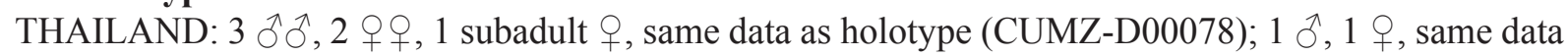
as holotype (ZMUC).

\section{Description}

Adult males with $58-62$ podous rings, no apodous rings. Length $12-14 \mathrm{~cm}$, width $7.1-8.0 \mathrm{~mm}$. Adult females with 59-62 podous rings, no apodous rings. Length $11-13 \mathrm{~cm}$, width $6.9-7.9 \mathrm{~mm}$. Colour in life unknown; preserved specimens with head, antennae, prozona, middorsal metazona and legs brown; metazona, epiproct, paraprocts and hypoproct reddish brown.

Gonopods (Fig. 3A-D). Anterior coxal fold ( $a c$; Fig. 3A): lateral process (alp) flattened, slightly curved, its laterodistal margin coarsely dentate, terminating in short, sharp, pointed spine; mesal process ( $\mathrm{amp}$ ) much shorter than alp, directed distad, tip curving mesad, pointed. Posterior coxal fold ( $p c$; Fig. 3B) basally with lateral paracoxites $(p x)$ quite low, distally with two processes: mesal process ( $p m p)$ very 
high, pointed-triangular, directed almost straightly distad; lateral process ( $p l p)$ much shorter, digitiform, directed distad and slightly laterad. Telopodite (Fig. 3C-D) leaving coxite over shelf of posterior coxal fold; femoral spine ( $f e$ ) duplicated, $f e 1$ projecting above top of telopodite curvature, curving backward, ending in slender barb, $f e 2$ basally broad, situated under $f e$ 1, curving backward, ending in slender barb;
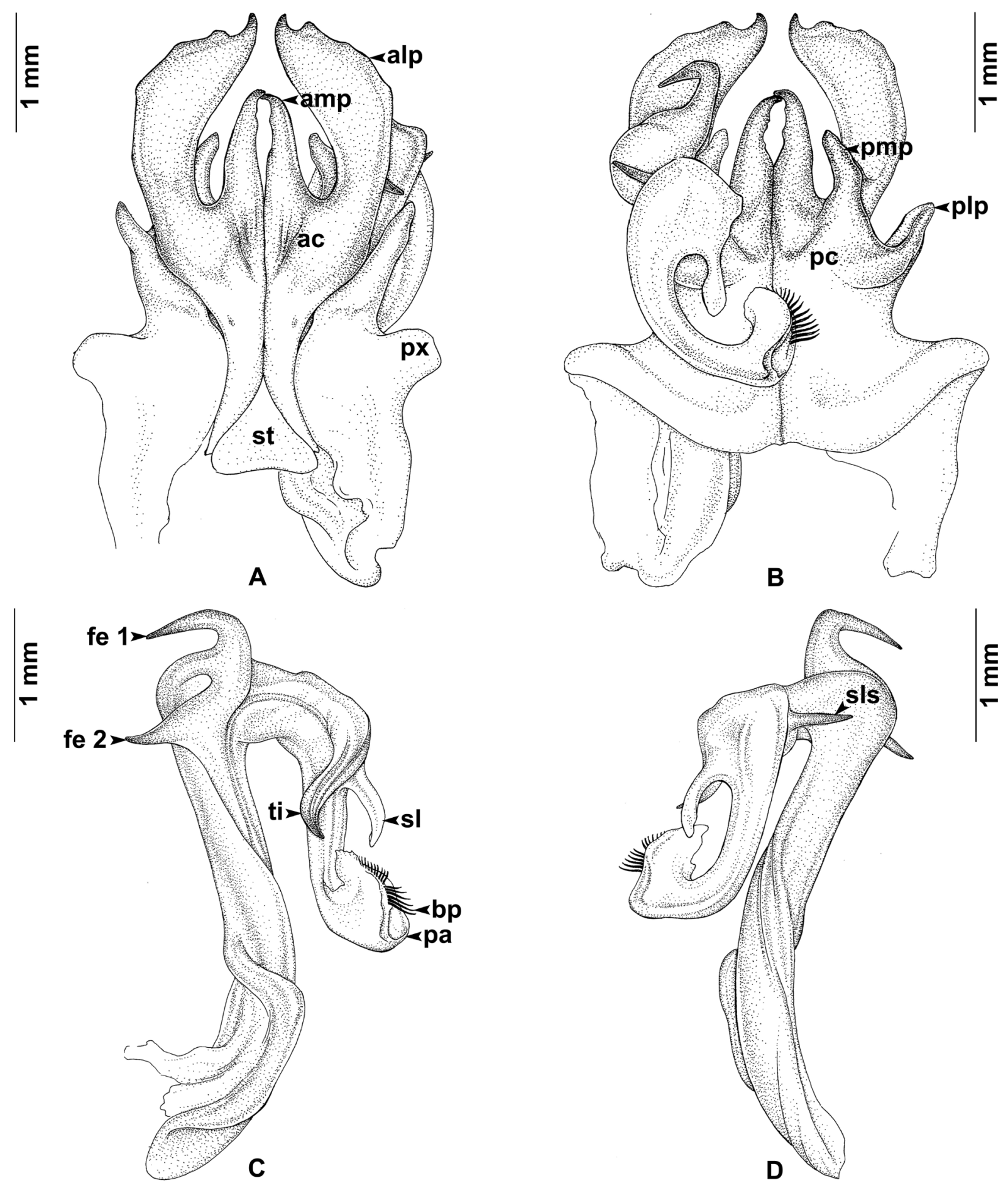

Fig. 3. Thyropygus culter sp. nov., from Rorn waterfall, holotype (CUMZ-D00091), ठ̂, gonopods. A. Anterior view, left telopodite removed. B. Posterior view, left telopodite removed. C. Left telopodite, posterior-mesal view. D. Left telopodite, anterior-lateral view. 
tibial spine ( $t i$ ) long, slender and recurved (not curving in horizontal plane); apical part: spatulate lobe $(s l)$ slender, rounded; with slender, long spine $(s l s)$ at base of apical part, opposite origin of tibial spine; palette $(p a)$ simple, distally with about twelve brownish blepharochaetae $(b p)$.

\section{DNA barcode}

The GenBank accession number of the barcode of one of the paratypes is KC519535 (voucher code CUMZ-D00078).

\section{Distribution (Fig. 12)}

Known only from the type locality.

\section{Thyropygus forceps sp. nov. urn:1sid:zoobank.org:act:11BAAEC5-404D-4E15-982C-2F3E51DEA56B}

Figs $4 \mathrm{~A}-\mathrm{E}, 11 \mathrm{~B}$

\section{Diagnosis}

A species of the opinatus subgroup. Lateral process of anterior coxal fold (alp) long, slender, regularly curved, tip close to tip of opposite alp, the two together forming a circle. Similar in this respect to T. erectus and T. floweri. Differs from the former by having a telopodite lobe $(l o)$. Particularly similar to T. floweri, differing from it by having the mesal process of posterior coxal fold ( $\mathrm{pmp}$ ) slender, directed distolaterad, laterally with a digitiform process $(p l p)$, and by not having $p m p$ strongly developed along the anterior-posterior axis.

\section{Etymology}

The name is a Latin noun in apposition, referring to the forceps-like gonopod coxae.

\section{Material examined}

Holotype

THAILAND: $\hat{0}$, Nakhonsrithammarat Province, Lanska District, Namwang Srithammasokrach, $8^{\circ} 20^{\prime} 25^{\prime \prime}$ N, 9949'42" E, 16 May 2010, leg. S. Panha, P. Pimvichai and members of the Animal Systematics Research Unit (CUMZ-D00092).

\section{Paratypes}

THAILAND: $2 \hat{\jmath} \hat{\partial}, 2$ subadult $\hat{\partial} \hat{\partial}$, same data as holotype (CUMZ-D00073); $5 \hat{\jmath} \hat{\jmath}$, Nakhonsrithammarat Province, Ronpiboon District, Tham Pha Deang temple, $8^{\circ} 14^{\prime} 42^{\prime \prime}$ N, $99^{\circ} 52^{\prime} 03^{\prime \prime}$ E, 14 May 2012, leg. C. Sutcharit and members of the Animal Systematics Research Unit (CUMZ-D00093); $2 \hat{\partial} \hat{\delta}$, same data as preceding (ZMUC).

\section{Description}

Adult males with 54-62 podous rings, no apodous rings. Length 9-12 cm, width 4.6-5.8 $\mathrm{mm}$. Overall colour of living animal (Fig. 11B) brown. Legs, antennae, middorsal metazona, epiproct, paraprocts and hypoproct brownish orange; preserved specimens with head, antennae, prozona, legs, middorsal metazona, epiproct, paraprocts and hypoproct brown; metazona dark brown.

Gonopods (Fig. 4A-E). Anterior coxal fold (ac; Fig. 4A): distinctly crenulated along convex part of lateral margin (smooth in specimens from Tham Pha Deang temple), lateral process (alp) long, slender, regularly curved, tip close to tip of opposite $a l p$, the two together forming a circle; mesal process ( $a m p$ ) slightly shorter than alp, directed obliquely disto-mesad (in specimens from Tham Pha Deang temple lateral process $(a l p)$ long, slender, crossing over with opposite tip, the two together forming a circle; 
Fig. 4B); mesal process ( $\mathrm{amp}$ ) slightly shorter than alp, directed distad, slightly sigmoid. Posterior coxal fold ( $p c$; Fig. 4C) basally with moderately high lateral paracoxites $(p x)$, distally with two processes: mesal process ( $\mathrm{pmp}$ ) slender, directed distolaterad; lateral process $(p l p)$ digitiform. Telopodite (Fig. 4D-E) leaving coxite over shelf of posterior coxal fold; femoral spine ( $f e$ ) massive, curving in horizontal plane and curving against $t i$; telopodite distally to $f e$ with large, round lobe $(l o)$ projecting distolaterally; tibial spine ( $t i$ ) very long, slender, curving in horizontal plane, its tip resting against base of $f e$; apical part: spatulate lobe $(s l)$ with sharp dark brown spine at tip; palette $(p a)$ simple, distally with about nine brownish blepharochaetae $(b p)$.

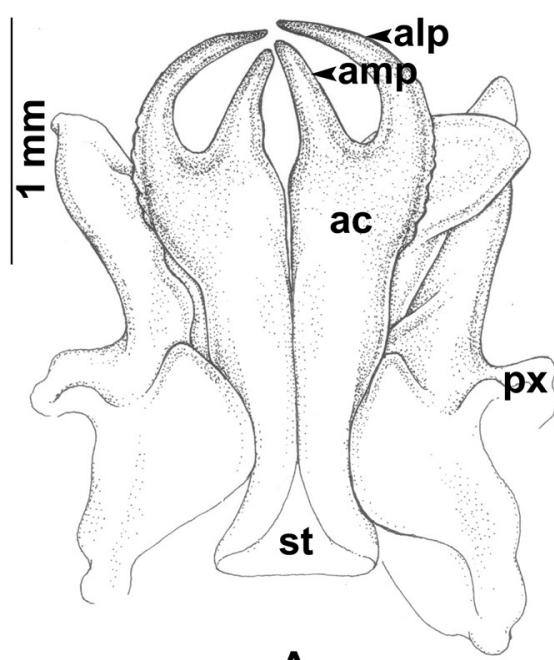

A

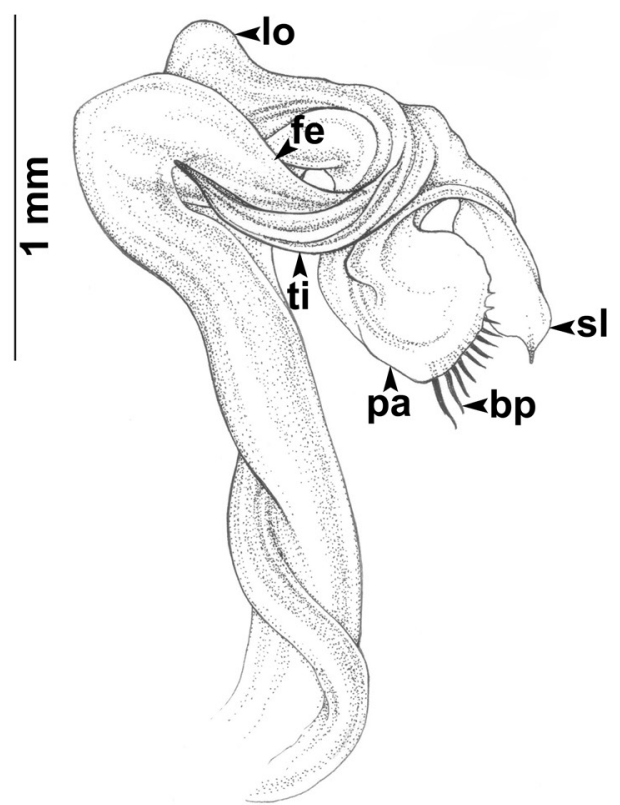

D

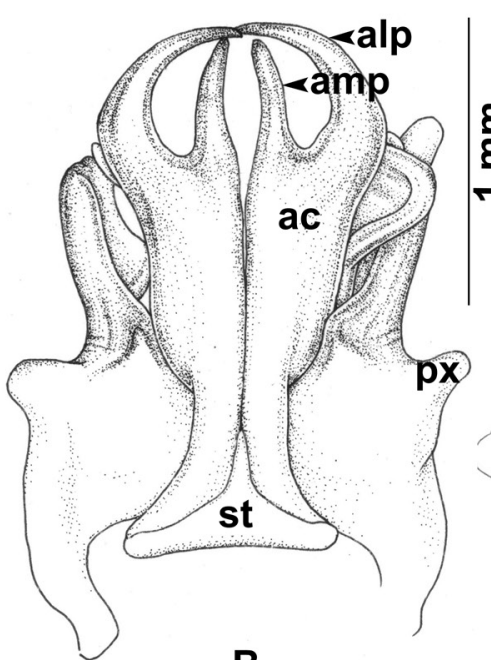

B

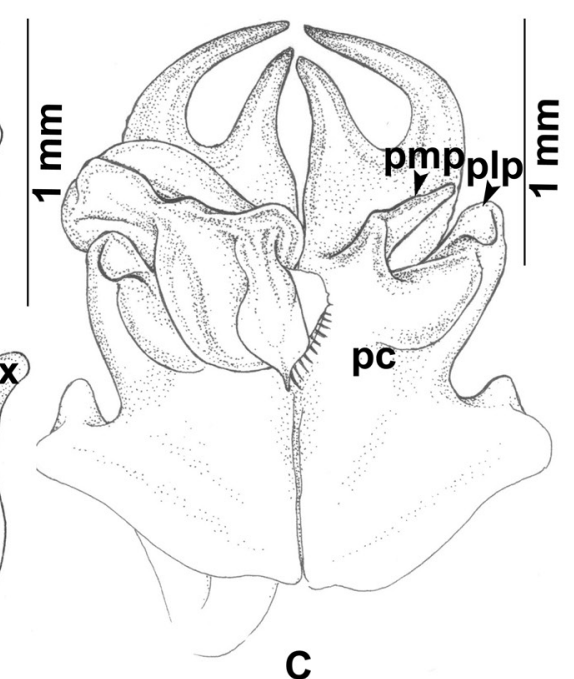

C

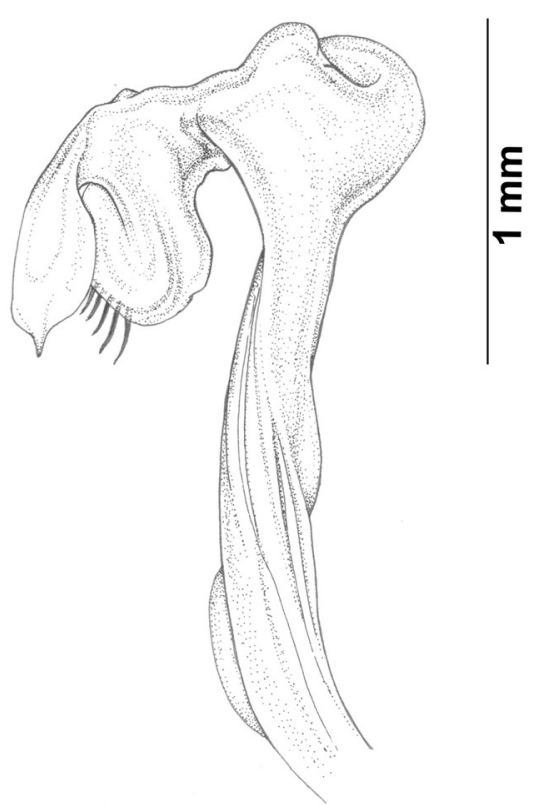

E

Fig. 4. Thyropygus forceps sp. nov., gonopods. - A, C-E. Holotype (CUMZ-D00092), §, from Namwang Srithammasokrach. A. Anterior view, left telopodite removed. C. Posterior view, left telopodite removed. D. Left telopodite, posterior-mesal view. E. Left telopodite, anterior-lateral view. - B. Specimen from Tham Pha Deang temple (CUMZ-D00093), ô. Anterior view, left telopodite removed. 


\section{DNA barcode}

The GenBank accession number of the barcode of one of the paratypes is KC519531 (voucher code CUMZ-D00073).

\section{Distribution (Fig. 12)}

Known only from Namwang Srithammasokrach and Tham Pha Deang temple in Nakhonsrithammarat Province.

\section{Remarks}

Coexisting with the larger T. cimi sp. nov. at Namwang Srithammasokrach.

Thyropygus mesocristatus $\mathrm{sp}$. nov. urn:1sid:zoobank.org:act:5D8F7830-2E8E-46E3-B2BE-830FC31F290D

Fig. 5A-E

\section{Diagnosis}

A species of the opinatus subgroup. Lateral process of anterior coxal fold (alp) slender, curving mesad; mesal process of anterior coxal fold ( $\mathrm{amp}$ ) as long as alp, slender, straight, directed distad. Similar in these respects to T. demangei. Differs from this species by having mesal margin of amp forming a strong longitudinal crest $(l c)$ in posterior view, by having only one femoral spine $(f e)$ and by having the spatulate lobe $(s l)$ broad and rounded.

\section{Etymology}

The name is a Latin adjective, referring to the longitudinal crest on the mesal process of the anterior coxal fold.

\section{Material examined}

\section{Holotype}

THAILAND: ${ }^{\lambda}$, Songkhla Province, Rattaphum District, Srikasorn, $7^{\circ} 00^{\prime} 18^{\prime \prime}$ N, 100 08'24" E, 12 Jan. 2009, leg. P. Pimvichai, C. Sutcharit and members of the Animal Systematics Research Unit (CUMZ-D00094).

\section{Paratype}

THAILAND: $\widehat{\jmath}$, same data as holotype (CUMZ-D00077).

\section{Description}

Adult males with $61-66$ podous rings, no apodous rings. Length $16-17 \mathrm{~cm}$, width $9.2-9.5 \mathrm{~mm}$. Colour in life unknown; preserved specimens with head, antennae, prozona and legs brown; metazona, epiproct, paraprocts and hypoproct reddish brown.

Gonopods (Fig. 5A-E). Anterior coxal fold (ac; Fig. 5A): lateral process (alp) slender, curving mesad, with lateral serrate crest near tip (Fig. 5C, arrow); mesal process (amp) as long as alp, slender, straight, directed distad, tip sharp, pointed, in posterior view mesal margin of amp forming strong longitudinal crest $(l c)$. Posterior coxal fold ( $p c$; Fig. 5B) basally with moderately high lateral paracoxites ( $p x)$, distally with two processes: mesal process ( $p m p)$ slender, directed anteriad; lateral process ( $p l p)$ short, erect, digitiform; forming shelf for accommodation of telopodite. Telopodite (Fig. 5D-E) leaving coxite between $p m p$ and $p l p$; femoral spine ( $f e$ ) long, curved downward, with expanded lamella at base; tibial spine (ti) very long, curving in horizontal plane, tip close to basal part of $f e$; small spine (ss) at base of apical part, opposite origin of tibial spine; spatulate lobe $(s l)$ broad, rounded; a small accessory lobe $(a l)$ 
at base of $s l$; palette $(p a)$ simple, gutter-like, with longitudinal crest ( $c r)$ at middle, distally with about twelve brownish blepharochaetae $(b p)$.

\section{DNA barcode}

The GenBank accession number of the barcode of the paratype is KC519534 (voucher code CUMZ-D00077).

\section{Distribution (Fig. 12)}

Known only from the type locality.

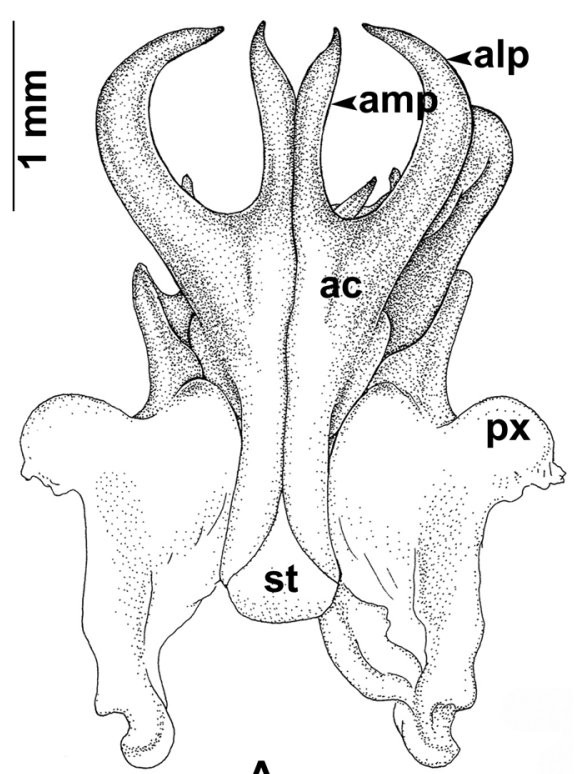

A

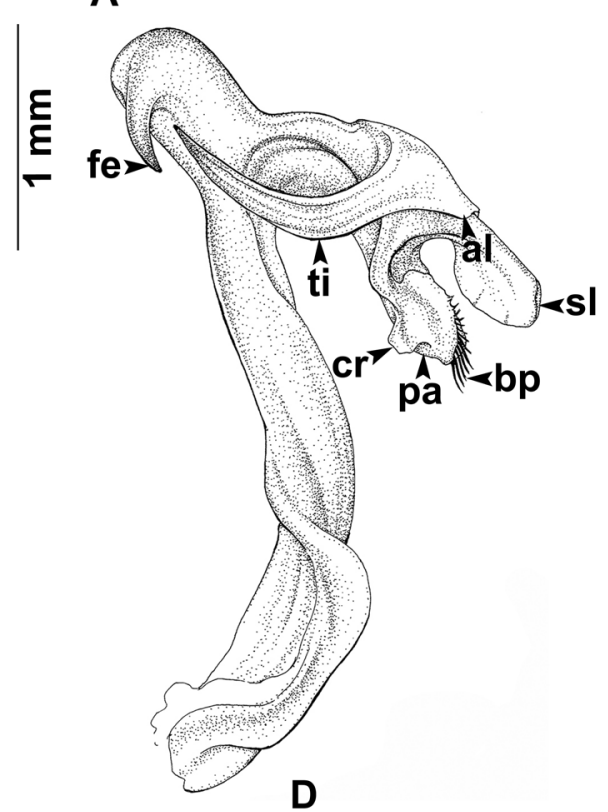

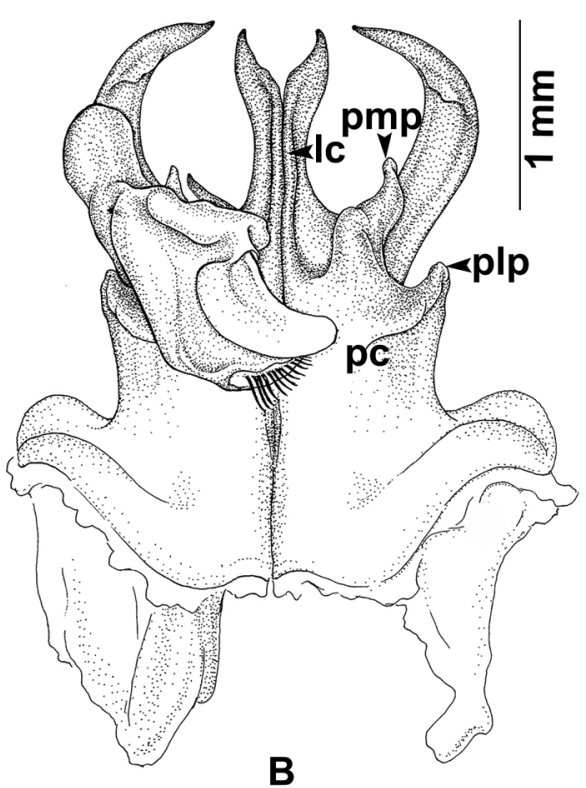

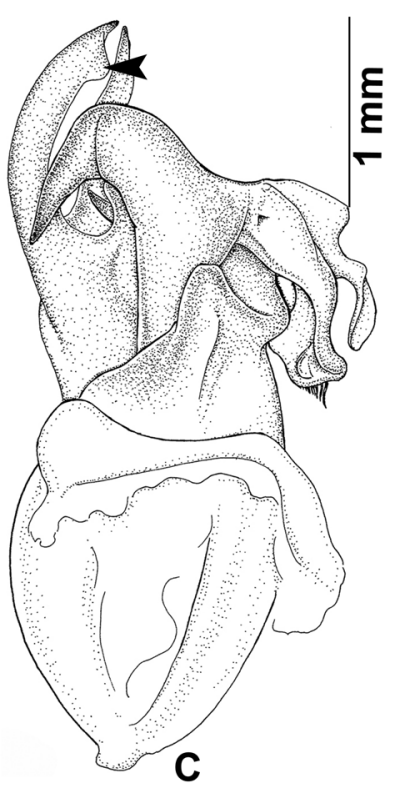

B

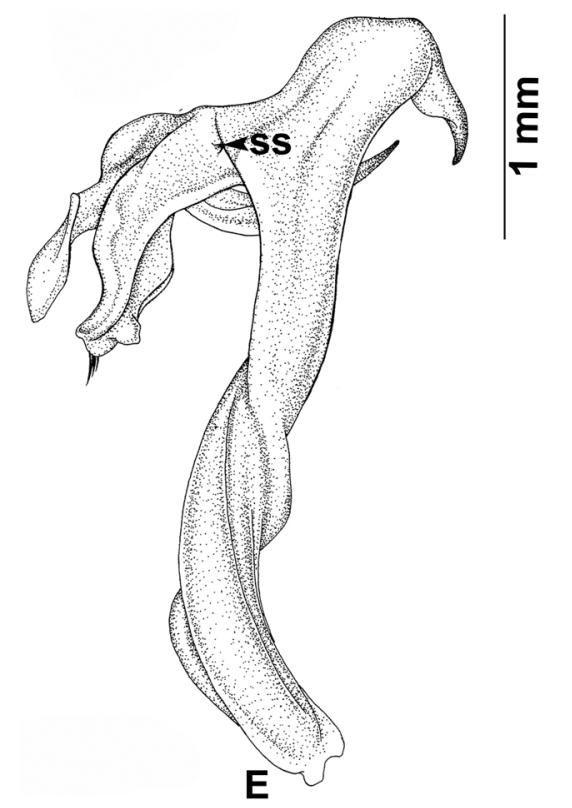

Fig. 5. Thyropygus mesocristatus sp. nov., from Srikasorn, holotype (CUMZ-D00094), đ̂, gonopods. A. Anterior view, left telopodite removed. B. Posterior view, left telopodite removed. C. Lateral view. D. Left telopodite, posterior-mesal view. E. Left telopodite, anterior-lateral view. 
Thyropygus navychula sp. nov.

urn:1sid:zoobank.org:act:01AC06C9-EEF0-4211-9837-28FE2C12C68E

Figs $6 \mathrm{~A}-\mathrm{D}, 11 \mathrm{~A}$

\section{Diagnosis}

A species of the opinatus subgroup. Mesal margin of anterior coxal fold (alp) with fine serrations. Similar in this respect to T. opinatus. Differs from this species by having the lateral process (alp)
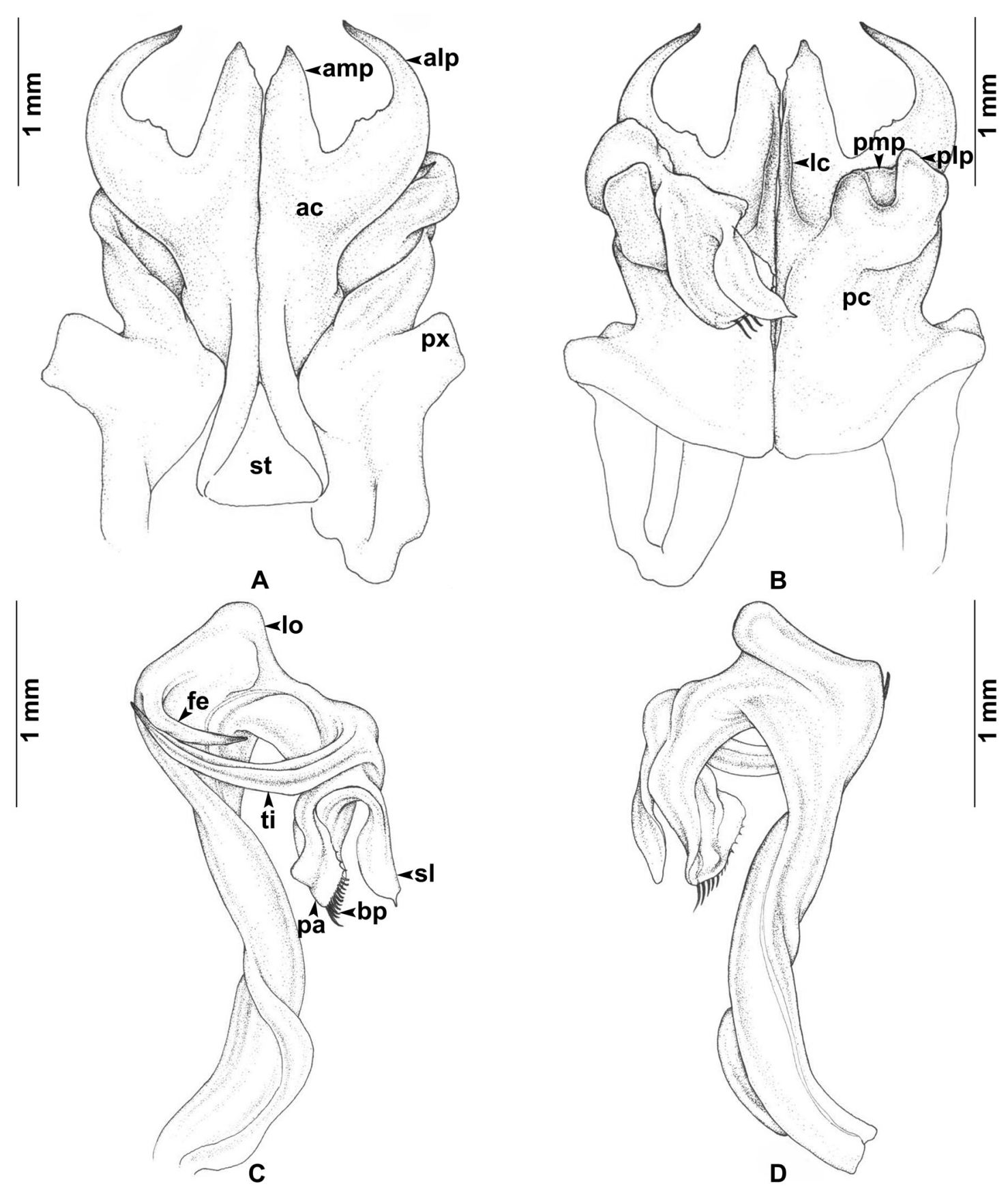

Fig. 6. Thyropygus navychula sp. nov., from Surin Islands, holotype (CUMZ-D00095), Ô, gonopods. A. Anterior view, left telopodite removed. B. Posterior view, left telopodite removed. C. Left telopodite, posterior-mesal view. D. Left telopodite, anterior-lateral view. 
slender, regularly curved and by having the mesal process ( $\mathrm{amp}$ ) broadly expanded and forming a strong longitudinal crest $(l c)$ in posterior view.

\section{Etymology}

The species is named after the Royal Thai Navy, in recognition of their kind assistance which enabled us to pursue the necessary fieldwork at the type locality, and also after Chulalongkorn University where pink is the symbolic colour of the university, indirectly referring to the pink legs of the species; the species name is treated as a noun in apposition.

\section{Material examined}

Holotype

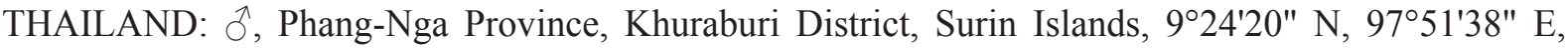
7 Apr. 2012, leg. S. Panha, P. Pimvichai and members of the Animal Systematics Research Unit (CUMZ-D00095).

\section{Paratypes}

THAILAND: $5 \hat{\jmath} \hat{\partial}, 1$ q, same data as holotype (CUMZ-D00089); $2 \hat{\partial} \hat{\sigma}$, same data as holotype (ZMUC).

\section{Description}

Adult males with 58-62 podous rings, no apodous rings. Length $11-12 \mathrm{~cm}$, width $6.2-7.2 \mathrm{~mm}$. Adult female with 60 podous rings, no apodous rings. Length $14 \mathrm{~cm}$, width $8.0 \mathrm{~mm}$. Overall colour of living animal (Fig. 11A) dark brown, shiny. Legs and antennae pink; preserved specimen with head, antennae, prozona, legs, epiproct, paraprocts and hypoproct brown; metazona dark brown.

Gonopods (Fig. 6A-D). Anterior coxal fold ( $a c$; Fig. 6A): lateral process (alp) slender, regularly curved, mesal margin with fine serrations; mesal process ( $\mathrm{amp}$ ) almost as long as alp, broadly expanded, apically sharp, straight distad, in posterior view mesal margin of amp forming strong longitudinal crest $(l c)$. Posterior coxal fold ( $p c$; Fig. 6B) basally with moderately high lateral paracoxites ( $p x)$, distally with two processes: mesal process ( $(\mathrm{m} p \mathrm{p}$ ) shorter than $p l p$, curving behind $p l p$; lateral process $(p l p)$ flattened, directed distad. Telopodite (Fig. 6C-D) leaving coxite between $p m p$ and $p l p$; femoral spine ( $f e$ ) very long, curving almost exclusively in horizontal plane; tibial spine $(t i)$ very long, curving in horizontal plane close to basal part of $f e$; spatulate lobe $(s l)$ terminating in sharp spine; palette $(p a)$ simple, gutterlike, distally with about twelve brownish blepharochaetae $(b p)$, laterally with few sharp spines.

\section{DNA barcode}

The GenBank accession number of the barcode of one of the paratype is KU306522 (voucher code CUMZ-D00089).

\section{Distribution (Fig. 12)}

Known only from the type locality.

Thyropygus planispina sp. nov. urn:1sid:zoobank.org:act:2F5A25A4-44CC-4B93-AC17-9A9B6E6E9E1F

Fig. 7A-E

\section{Diagnosis}

A species of the opinatus subgroup. Differs from all other species in the subgroup by having the lateral process of the anterior coxal fold (alp) regularly curved, terminating in a sharp spine pointing slightly distad, and by having the tibial spine ( $t i)$ short and flattened. 


\section{Etymology}

The name is a Latin noun in apposition and refers to the flattened tibial spine ( $t i)$.

\section{Material examined}

\section{Holotype}

THAILAND: $\widehat{ }{ }^{\curvearrowright}$, Krabi Province, Muang District, Tham Sua temple, $8^{\circ} 07^{\prime} 30^{\prime \prime}$ N, 98 $55^{\circ} 30^{\prime \prime}$ E, 15 Jan. 2012, leg. P. Pimvichai, C. Sutcharit and members of the Animal Systematics Research Unit (CUMZ-D00088).

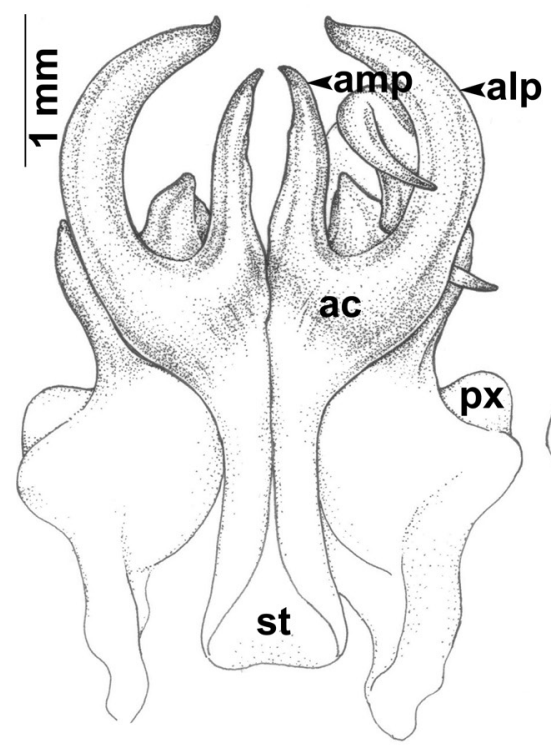

A

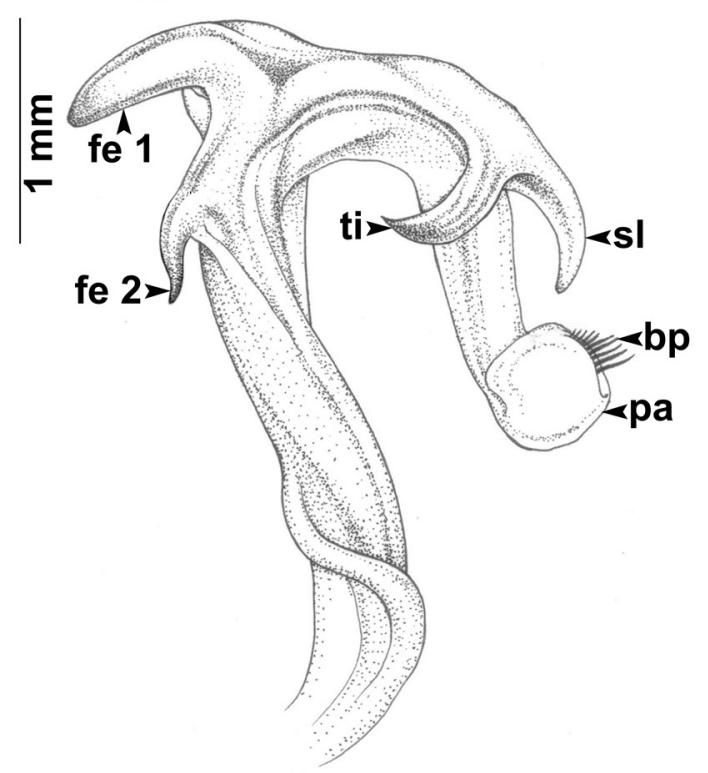

D

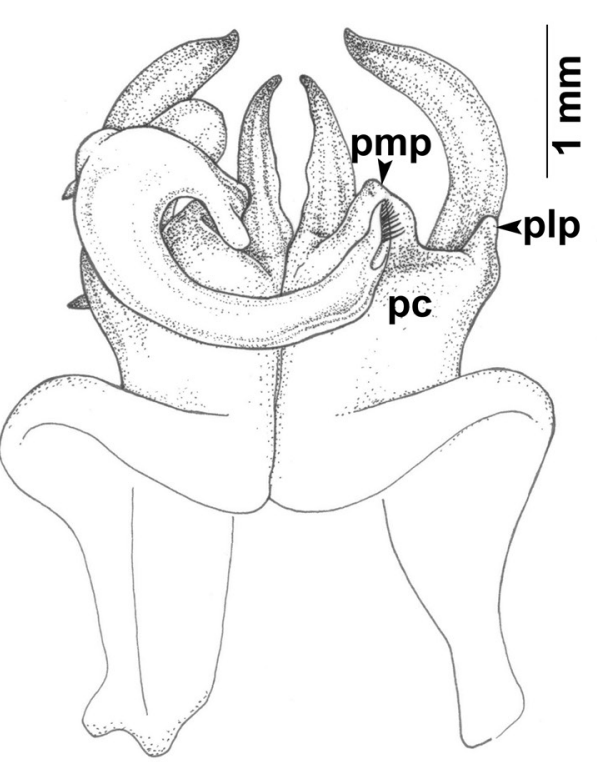

B

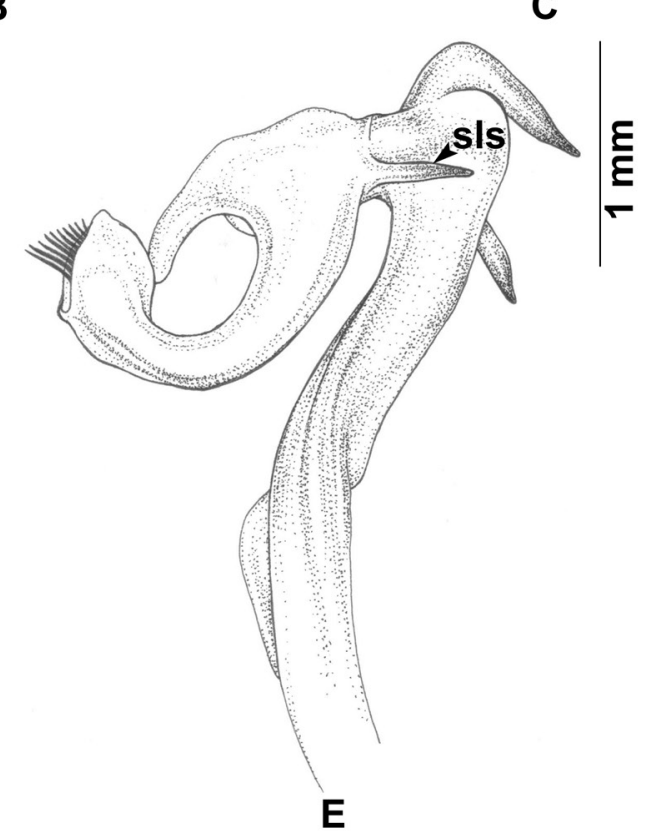

Fig. 7. Thyropygus planispina sp. nov., from Tham Sua temple, holotype (CUMZ-D00088), §̂, gonopods. A. Anterior view, left telopodite removed. B. Posterior view, left telopodite removed. C. Lateral view. D. Left telopodite, posterior-mesal view. E. Left telopodite, anterior-lateral view. 
Paratypes

THAILAND: 3 우, same data as holotype (CUMZ-D00097).

\section{Description}

Adult male with 64 podous rings, no apodous rings. Length $13 \mathrm{~cm}$, width $7.6 \mathrm{~mm}$. Adult females with 60-63 podous rings, no apodous rings. Length $13-14 \mathrm{~cm}$, width $7.8-8.6 \mathrm{~mm}$. Colour in life unknown; preserved specimens with head, antennae, legs, metazona, epiproct, paraprocts and hypoproct brown; prozona yellowish brown.

Gonopods (Fig. 7A-E). Anterior coxal fold (ac; Fig. 7A): lateral process (alp) regularly curved, terminating in sharp spine pointing slightly distad, with lateral short, sharp crest at middle of alp (Fig. 7C, arrow); mesal process (amp) slightly shorter than alp, flattened, straight, directed distad. Posterior coxal fold ( $p c$; Fig. 7B) basally with moderately high lateral paracoxites ( $p x)$, distally truncate, forming shelf for accommodation of telopodite, mesal process ( process ( $p l p)$ erect, digitiform. Telopodite (Fig. 7D-E) leaving coxite over shelf of posterior coxal fold; femoral spine double, $f e l$ very long, curved downward, situated above $f e 2$, in situ resting at middle of alp, fe 2 long, very slender, curved downward; tibial spine (ti) flattened, short, curving mesad; apical part: spatulate lobe $(s l)$ small, rounded; with slender, long spine $(s l s)$ at base of apical part; palette $(p a)$ simple, gutter-like, distally with about nine brownish blepharochaetae $(b p)$.

\section{DNA barcode}

The GenBank accession number of the barcode of the holotype is KU306521 (voucher code CUMZ-D00088).

Distribution (Fig. 12)

Known only from the type locality.

Thyropygus sutchariti sp. nov. urn:Isid:zoobank.org:act:6804DF2C-7787-46FE-9185-2E5C40AF5ED3

Fig. $8 \mathrm{~A}-\mathrm{D}$

\section{Diagnosis}

A species of the opinatus subgroup. Mesal process of anterior coxal fold ( $\mathrm{amp}$ ) directed slightly obliquely disto-mesad, tip overlapping tip of opposite amp. Similar in this respect to T. chelatus. Differs from this species by having amp as long as alp and by having the lateral process of the posterior coxal fold ( $p l p)$ as a massive, broad lobe.

\section{Etymology}

The species is named in honour of Chirasak Sutcharit in recognition of his devotion to collecting millipedes.

\section{Material examined}

Holotype

THAILAND: $\widehat{\text {, }}$, Phetchaburi Province, Kaeng Krachan District, Kaeng Krachan, 12 $54^{\prime} 07^{\prime \prime}$ N, 99³5'56" E, 14 May 2012, leg. C. Sutcharit and members of the Animal Systematics Research Unit (CUMZ-D00090).

\section{Paratypes}

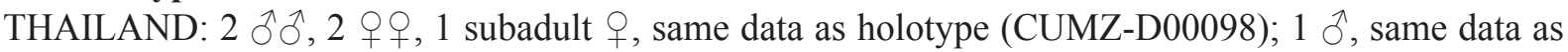
holotype (ZMUC). 


\section{Description}

Adult males with $63-65$ podous rings, no apodous rings. Length $10-11 \mathrm{~cm}$, width $5.4-5.7 \mathrm{~mm}$. Adult females with 61-63 podous rings, no apodous rings. Length $12-13 \mathrm{~cm}$, width $6.7-6.9 \mathrm{~mm}$. Colour in life unknown; preserved specimens with head, antennae, prozona, legs, epiproct, paraprocts and hypoproct brown; metazona reddish brown.
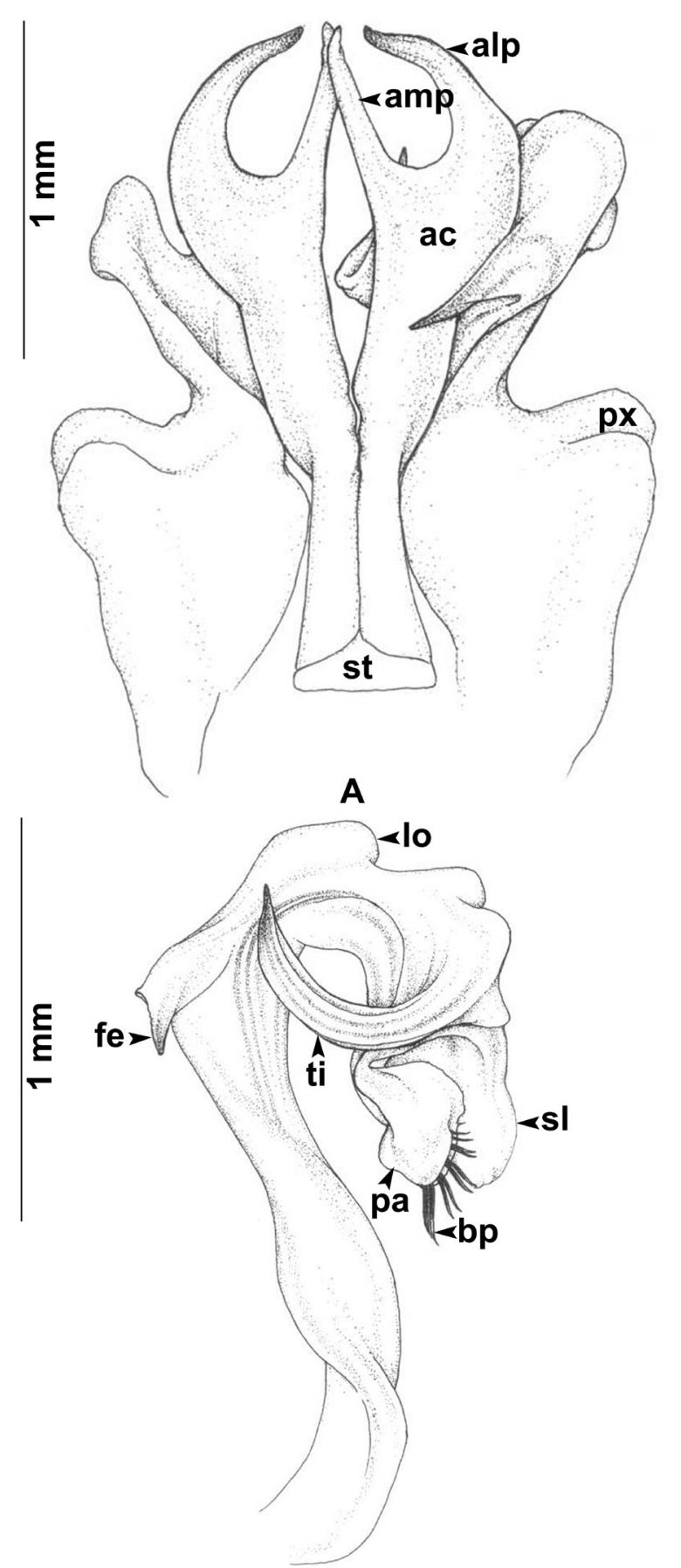

C

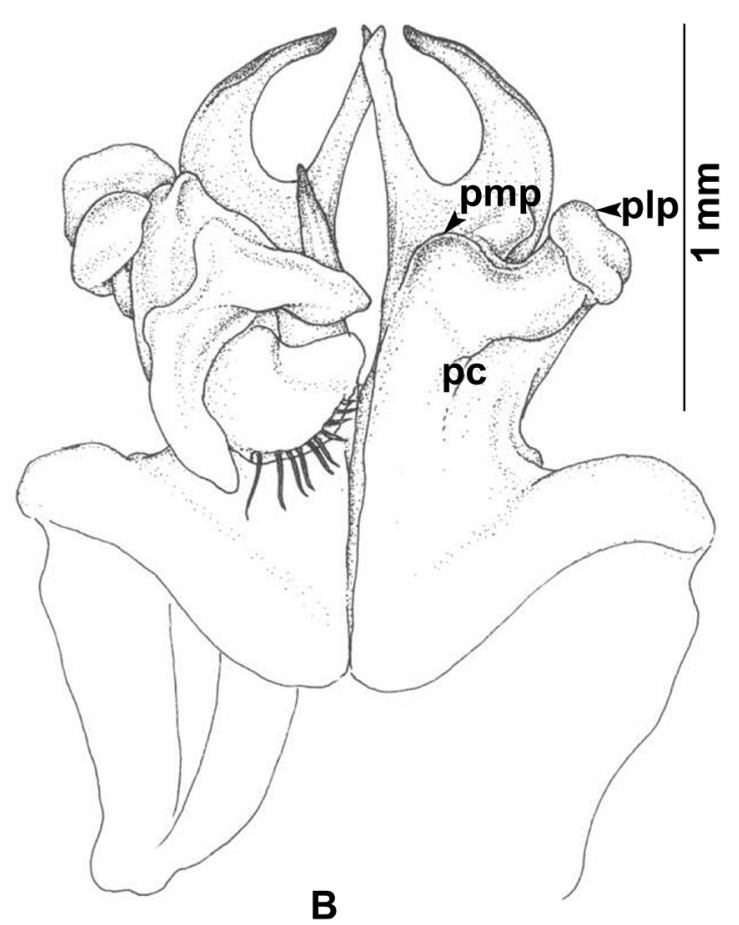

B

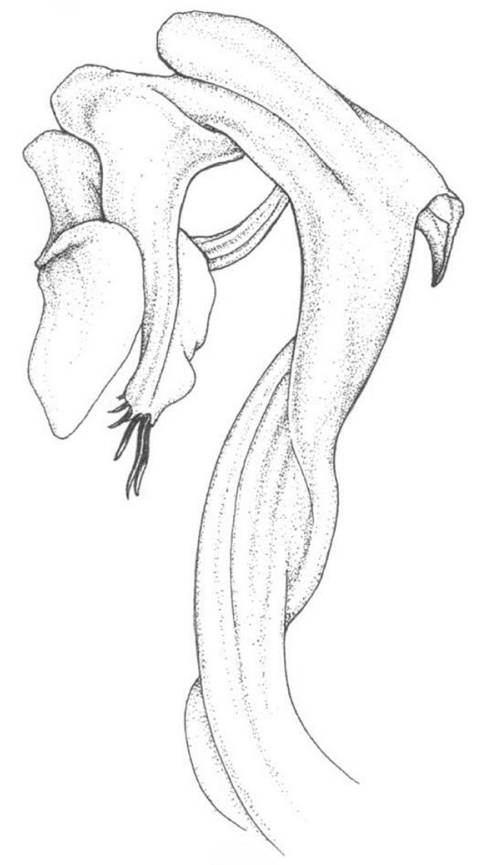

D

Fig. 8. Thyropygus sutchariti sp. nov., from Kaeng Krachan, holotype (CUMZ-D00090), đ̃, gonopods. A. Anterior view, left telopodite removed. B. Posterior view, left telopodite removed. C. Left telopodite, posterior-mesal view. D. Left telopodite, anterior-lateral view. 
Gonopods (Fig. 8A-D). Anterior coxal fold ( $a c$; Fig. 8A): lateral process (alp) slender, regularly curved; mesal process $(\mathrm{amp})$ as long as alp, directed slightly obliquely disto-mesad, tip overlapping tip of opposite amp. Posterior coxal fold ( $p c$; Fig. $8 \mathrm{~B})$ basally with moderately high lateral paracoxites $(p x)$, distally with two processes: mesal process ( $\mathrm{pmp}$ ) a rounded lobe; lateral process ( $p l p)$ a massive, broad lobe, projecting laterad. Telopodite (Fig. 8C-D) leaving coxite between $p m p$ and $p l p$; femoral spine ( $f e$ ) long, curved downward; telopodite distally to $f e$ with large, round lobe (lo) projecting distolaterally; tibial spine ( $t i)$ very long, curving in horizontal plane, tip close to basal part of $l o$; spatulate lobe $(s l)$ broad, rounded; palette $(p a)$ simple, gutter-like, distally with about ten brownish blepharochaetae $(b p)$.

\section{DNA barcode}

The GenBank accession number of the barcode of the holotype is KU306524 (voucher code CUMZ-D00090).

\section{Distribution (Fig. 12)}

Known only from the type locality.

Thyropygus undulatus sp. nov. urn:lsid:zoobank.org:act:972296F7-CF7B-4AD4-A2AA-3DCE22596B3E

Fig. 9A-E

\section{Diagnosis}

A species of the opinatus subgroup. Lateral process ( $a l p$ ) flattened, slightly curved, its laterodistal margin coarsely dentate. Similar in this respect to T. cristagalli, T. implicatus and T. culter sp. nov. Differs from these species by having the mesal process of the posterior coxal fold ( $\mathrm{pmp}$ ) with two rounded distal lobes, visible in anterior view between alp and $a m p$, and by having the tibial spine ( $t i)$ not ending in a sharp point.

\section{Etymology}

The name is a Latin adjective, referring to the undulate/coarsely dentate laterodistal margin of the lateral process of the anterior coxal fold.

\section{Material examined}

Holotype

THAILAND: $\widehat{\partial}$, Krabi Province, Muang District, Khao Phanom Bencha, $8^{\circ} 16^{\prime} 30^{\prime \prime}$ N, $98^{\circ} 55^{\prime} 30^{\prime \prime} \mathrm{E}$, 16 Jan. 2009, leg. P. Pimvichai, C. Sutcharit and members of the Animal Systematics Research Unit (CUMZ-D00087).

\section{Paratypes}

THAILAND: 1 , same data as holotype (CUMZ-D00099).

\section{Description}

Adult male with 63 podous rings, no apodous rings. Length $15 \mathrm{~cm}$, width $8.7 \mathrm{~mm}$. Adult female with 64 podous rings, no apodous rings. Length $14 \mathrm{~cm}$, width $8.5 \mathrm{~mm}$. Colour in life unknown; preserved specimens with head, legs, middorsal metazona, epiproct, paraprocts and hypoproct brown; antennae and metazona dark brown; prozona whitish-brown.

Gonopods (Fig. 9A-E). Anterior coxal fold ( $a c$; Fig. 9A): lateral process (alp) flattened, curving mesad, its laterodistal margin coarsely dentate, terminating in a short spine, tip curving against tip of opposite side, lateral margins with serrate crest (Fig. 9C, arrow); mesal process (amp) much shorter than alp, 
slender, curving mesad. Posterior coxal fold ( $p c$; Fig. 9B) basally with moderately high lateral paracoxites $(p x)$; mesal process ( $\mathrm{pmp}$ ) distally with two rounded lobes, visible in anterior view between alp and amp; lateral process ( $p l p$ ) erect, digitiform. Telopodite (Fig. 9D-E) leaving coxite over shelf of posterior coxal fold; femoral spine ( $f e$ ) duplicated, $f e 1$ relatively long, projecting above top of telopodite, curving backward, ending in slender barb, $f e 2$ basally broad, situated under $f e$, curving backward, ending in slender barb; tibial spine (ti) long, curving in horizontal plane, not ending in sharp spine; apical part: spatulate lobe $(s l)$ rounded, with slender long spine $(s l s)$ at base of apical part, opposite origin of tibial spine; palette ( $p a)$ simple, distally with about eleven brownish blepharochaetae $(b p)$.

\section{DNA barcode}

The GenBank accession number of the barcode of the holotype is KU306520 (voucher code CUMZ-D00087).

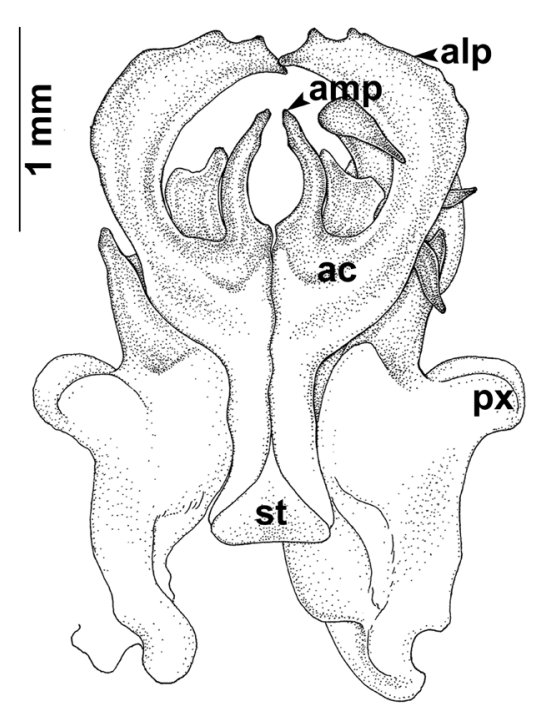

A

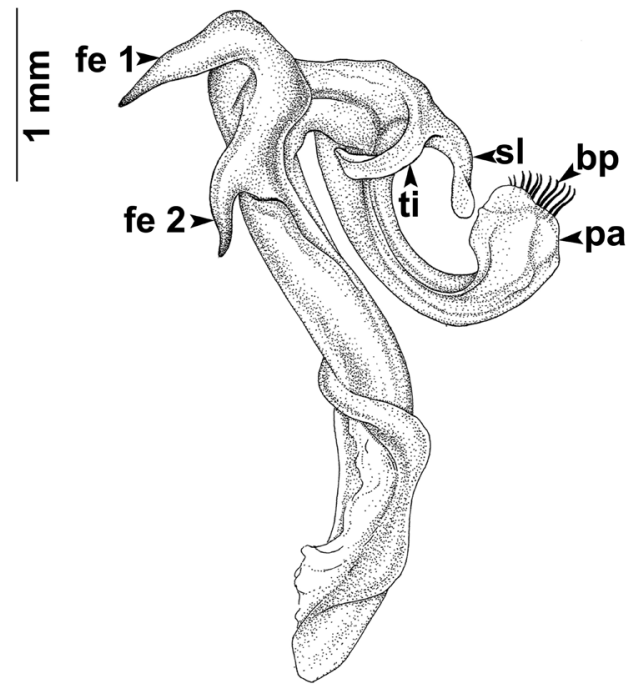

D

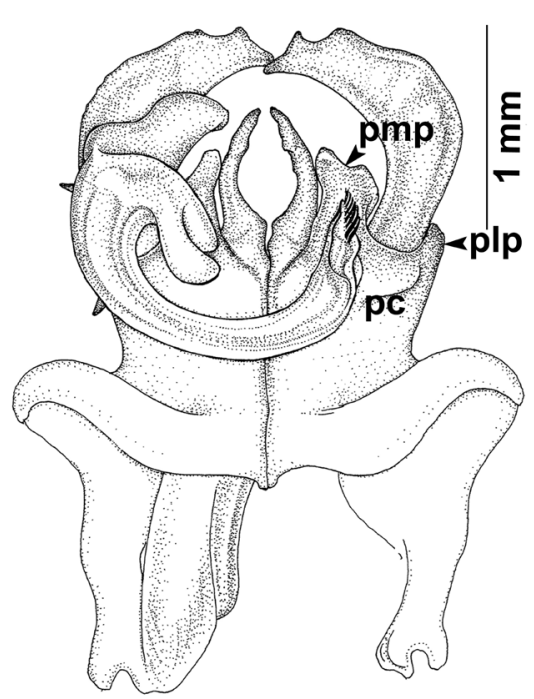

B

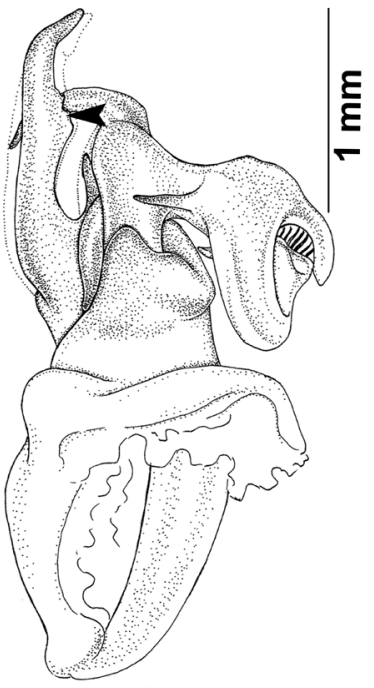

C

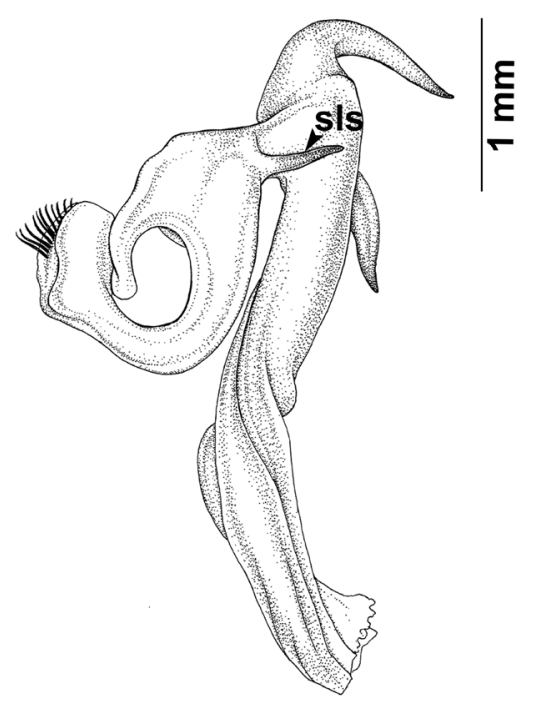

$\mathbf{E}$

Fig. 9. Thyropygus undulatus sp. nov., from Khao Phanom Bencha, holotype (CUMZ-D00087), ठ̃, gonopods. A. Anterior view, left telopodite removed. B. Posterior view, left telopodite removed. C. Lateral view. D. Left telopodite, posterior-mesal view. E. Left telopodite, anterior-lateral view. 
Distribution (Fig. 12)

Known only from the type locality.

Thyropygus ursus sp. nov. urn:1sid:zoobank.org:act:D3E091F2-C075-458B-A9B5-DA35B673309B

Fig. 10A-D

\section{Diagnosis}

A species of the opinatus subgroup. Differs from all other species in the subgroup by having the lateral process of the anterior coxal fold (alp) flattened, broad, apically curved caudad and ending in a short spine, as well as by the first femoral spine $(f e l)$ being very short and erect.

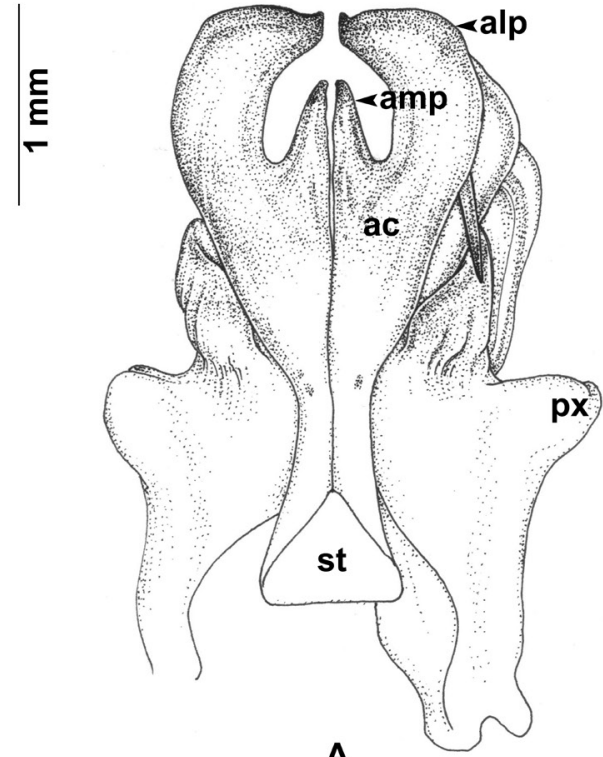

A

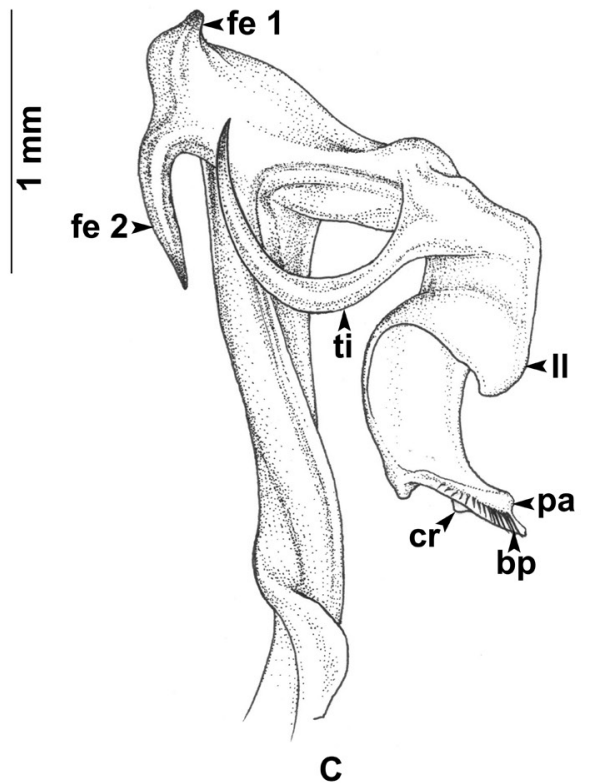

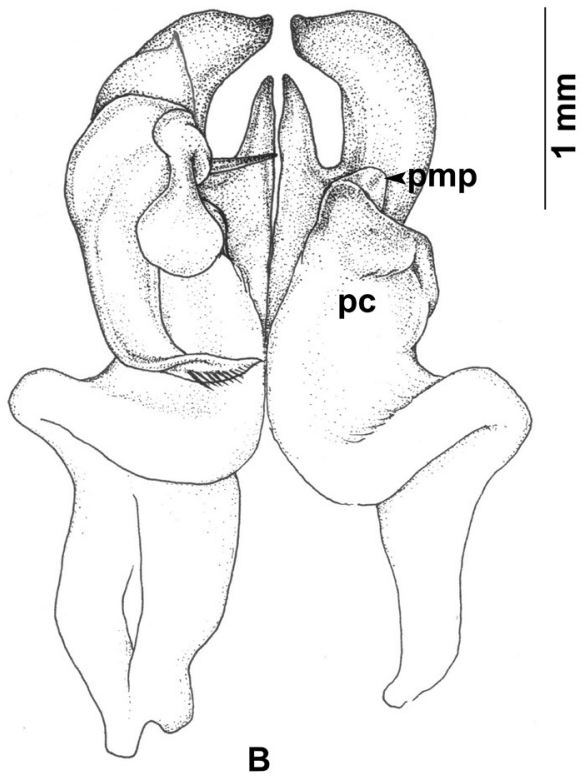

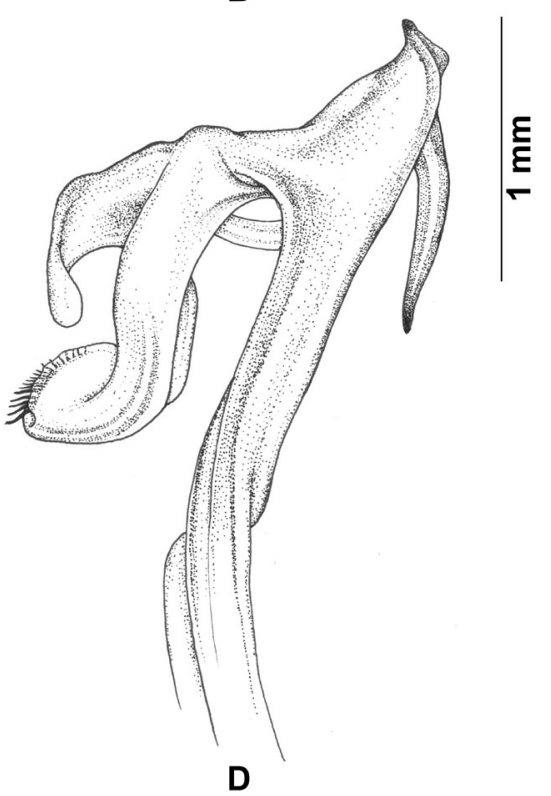

Fig. 10. Thyropygus ursus sp. nov., from Lanta Islands, holotype (NMHW-Inv.7855), §̂, gonopods. A. Anterior view, left telopodite removed. B. Posterior view, left telopodite removed. C. Left telopodite, posterior-mesal view. D. Left telopodite, anterior-lateral view. 


\title{
Etymology
}

The name is a Latin noun in apposition, meaning "bear", and refers to the (somewhat) bearhead-like profile of the lateral process of the anterior coxal fold (alp).

\section{Material examined}

\section{Holotype}

THAILAND: $\widehat{\jmath}$, Krabi Province, Koh Lanta District, Lanta Islands, 7³9'20" N, 9902'31" E, 2 Jan. 2009, leg. B. Däubl and E. Haring (NMHW-Inv.7855).

\author{
Paratypes \\ THAILAND: 1 , same data as holotype (NMHW).
}

\section{Description}

Adult male with 62 podous rings, no apodous rings. Length $11 \mathrm{~cm}$, width $6.4 \mathrm{~mm}$. Adult female with 61 podous rings, no apodous rings. Length $12 \mathrm{~cm}$, width $7.4 \mathrm{~mm}$. Colour in life unknown; preserved specimens with head, antennae, legs, metazona, epiproct, paraprocts and hypoproct brown; prozona yellowish brown.

Gonopods (Fig. 10A-D). Anterior coxal fold (ac; Fig. 10A): lateral process (alp) flattened, broad, apically curved caudad, tip with short spine, lateral margin slightly folded; mesal process (amp) shorter than alp, slender, straight, directed distad, pointed. Posterior coxal fold ( $p c$; Fig. 10B) basally with moderately high paracoxites $(p x)$, distally truncate, forming shelf to accommodate telopodite, mesal process ( $p m p)$ very small, directed distolaterad. Telopodite (Fig. 10C-D) leaving coxite over shelf of posterior coxal fold; femoral spine double, fe 1 very short, erect, situated above $f e$, fe 2 very long, slender, curved downward, in situ resting behind alp; tibial spine (ti) long, slender, curving in horizontal plane, its tip close to base of $f e$; apical part: lamellar lobe $(l l)$ broad, bent down; palette $(p a)$ simple, gutter-like, with small crest (cr) near tip; distally with about twelve brownish blepharochaetae $(b p)$.

\section{DNA barcode}

The GenBank accession number of the barcode of the holotype is KU306523 (voucher code NMHWInv.7855).

\section{Distribution (Fig. 12)}

Known only from the type locality.
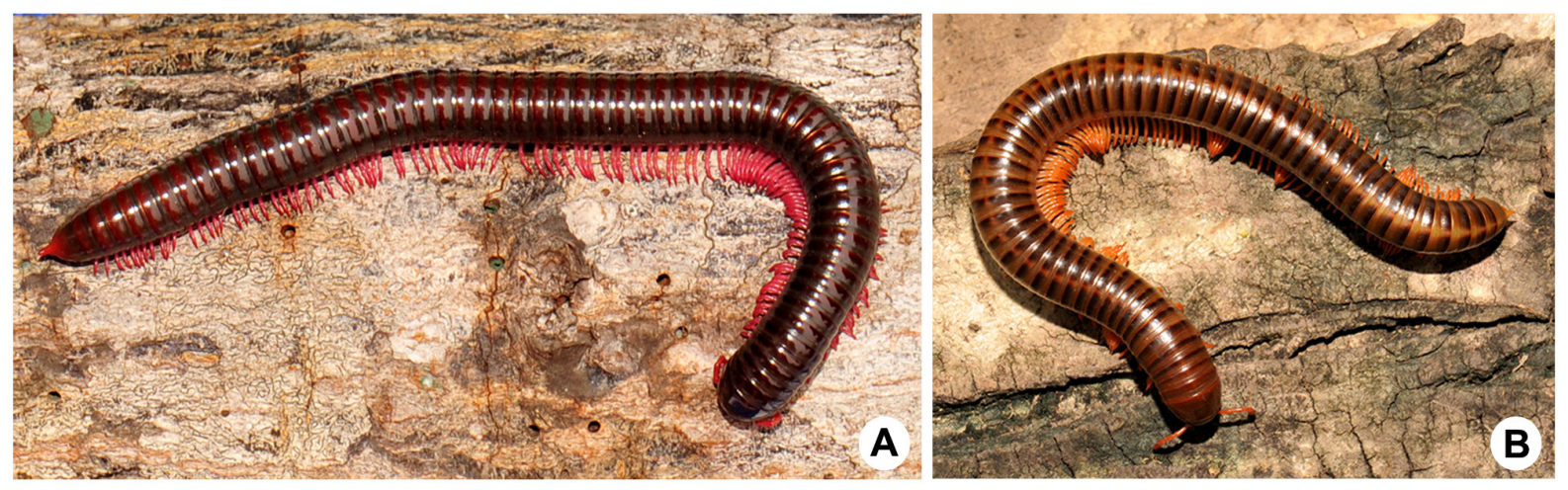

Fig. 11. A. Thyropygus navychula sp. nov., specimen from Surin Islands, living $\widehat{O}$ (paratype, CUMZ-D00089-1). B. Thyropygus forceps sp. nov., specimen from Namwang Srithammasokrach, living ổ (paratype, CUMZ-D00073-1). 


\section{Discussion}

In our previous treatment of the T. opinatus subgroup (Pimvichai et al. 2009a) we anticipated that DNA sequence data would help resolve relationships between Thyropygus species. A subsequent study (Pimvichai et al. 2014), which included a mtDNA sequence analysis of 23 Thyropygus species, did indeed shed light over these relationships. The present study expands the taxonomic coverage of this latter analysis by adding 9 new species to the mtDNA dataset. The analysis clearly shows that the opinatus and bifurcus subgroups cannot be maintained as separate groups and hence should be merged into an extended opinatus subgroup. The monophyly of this (extended) opinatus subgroup is wellsupported (Fig. 1). However, the phylogenetic relationships within the opinatus subgroup are often not well-resolved. Thus, still more species and nuclear genes need to be added to improve the phylogenetic resolution.

For the delimitation of species in the opinatus subgroup we used both gonopodal characters and divergences in COI sequences (Table 2). Interspecific distances among Bavarian Diplopoda ranged

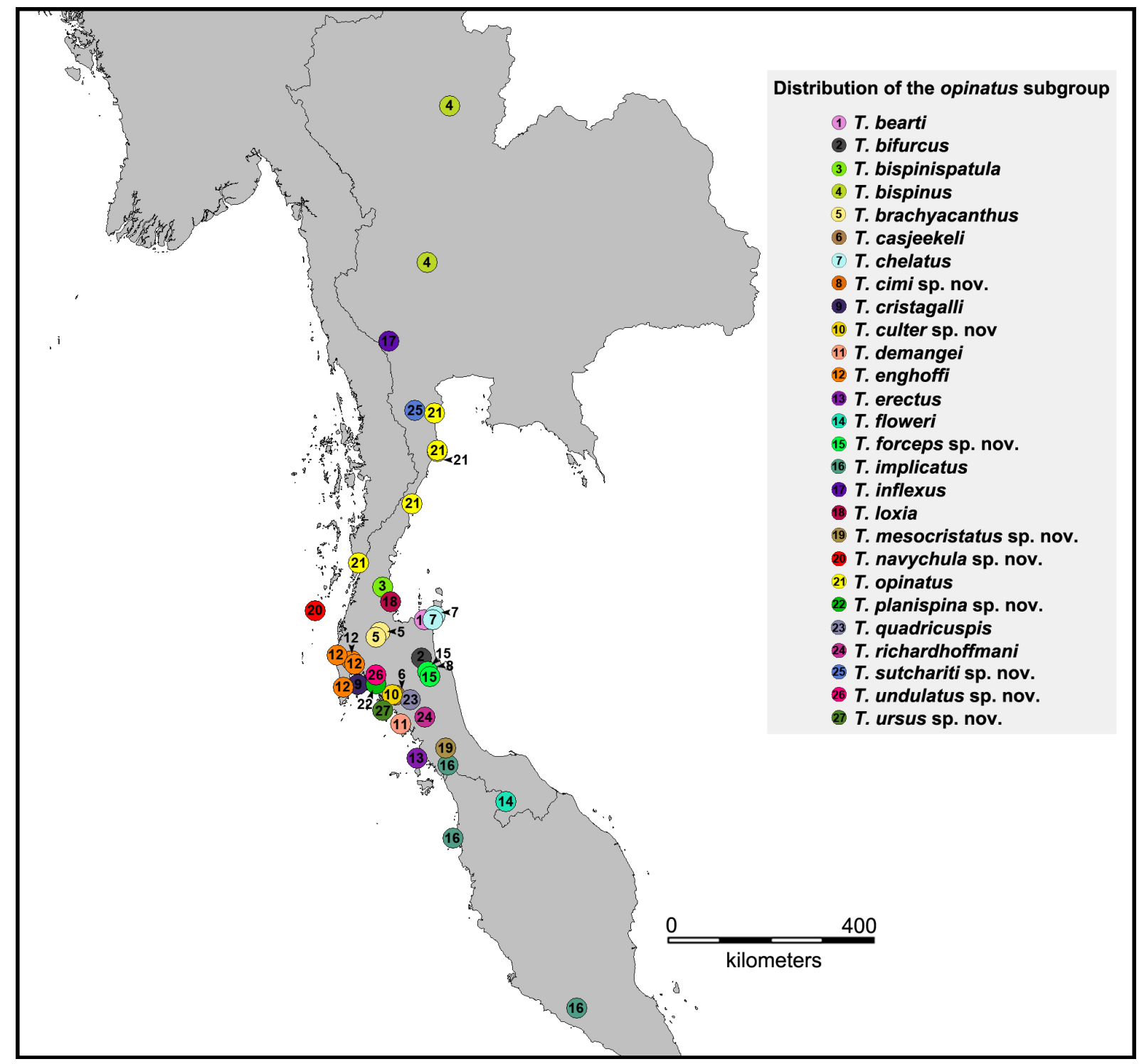

Fig. 12. Known distribution of the species of the T. opinatus subgroup. 
between $0 \%$ (in subspecies) and $33.18 \%$ (among different orders). The mean value of the interspecific distance for Diplopoda was $14.17 \%$ (Spelda et al. 2011). For 21 species of the opinatus subgroup the divergence was between 2 and $17 \%$. The lowest interspecific divergence was $2 \%$, between $T$. cristagalli and T. planispina sp. nov., between T. planispina sp. nov. and T. undulatus sp. nov., and between T. quadricuspis and T. ursus sp. nov. In these cases, speciation may have been very recent but we still need more DNA data and more samples to be able to infer the taxonomic status and relationships among these species properly. However, all these species show unique gonopodal characters and occur in separate localities and hence, for the time being, we treat these "morphs" as separate species. Nevertheless, intraspecific divergence of $T$. induratus was also $2 \%$ in the samples of the present study but despite this sequence divergence the overall gonopod configuration remained the same in the specimens here assigned to $T$. induratus.

All species of the opinatus subgroup share a conspicuous synapomorphy, viz. the additional projection on the anterior coxal fold. This character separates the opinatus subgroup from other subgroups of the T. allevatus group.

The main gonopodal variations within the opinatus subgroup are:

- the number of femoral spines $(f e)$ : one or two

- presence/absence of a spatulate lobe $(s l)$

- presence/absence of a longitudinal rounded crest ( $c r$ ) near the tip of the palette

- presence/absence of a small spine $(s s)$ or a slender long spine $(s l s)$ at the posterior base of the apical part of the telopodite

- presence/absence of a lateral $(p l p)$ and a mesal ( $p m p)$ process of the posterior coxal fold

The vast majority of the species we have studied and of the previous records of the T. opinatus subgroup are from the southern part of Thailand (Fig. 12). The remaining material comes from the North and West of Thailand and from some adjacent areas in Myanmar and Malaysia. Most probably further fieldwork in all these areas will lead to the discovery of further new species of Thyropygus.

\section{Acknowledgements}

This research was funded by the Thailand Research Fund (TRF-MRG5680056) to PP. PP was also funded by an EC Marie Curie Postdoctoral Fellowship to non EU-researchers issued by the Belgian Science Policy Office (BELSPO). Additional funding came from the Thailand Research Fund (TRF) as a TRF Senior Research Scholar (2015-2018; RTA 5880002) to SP. We express our sincere gratitude to the Plant Genetic Conservation Project initiated by her Royal Highness Princess Maha Chakri Sirindhorn, and the Navy Special Warfare Unit of the Royal Thai Navy for their kind assistance and encouragement, which enabled us to pursue the necessary fieldwork at Surin Islands and Lanta Islands, Phang-Nga Province. We also thank members of the Animal Systematics Research Unit, Chulalongkorn University for assistance in collecting specimens, especially to Dr. Chirasak Sutcharit, to Dr. Verena Stagl (NHMW) who provided specimens from Lanta Islands, and to Thita Krutchuen for the excellent drawings.

\section{References}

Akaike H. 1974. A new look at the statistical model identification. IEEE Transactions on Automatic Control 19 (6): 716-723. http://dx.doi.org/10.1109/TAC.1974.1100705

Darriba D., Taboada G.L., Doallo R. \& Posada D. 2012. jModelTest 2: more models, new heuristics and parallel computing. Nature Methods 9 (8): 772 . http://dx.doi.org/10.1038/nmeth.2109

Demange J.-M. 1961. Matériaux pour servir à une révision des Harpagophoridae (Myriapodes Diplopodes). Mémoires du Muséum national d'Histoire naturelle, Sér. A (Zool.) 24: 1-274. 
Demange J.-M. 1986. Harpagophoridae de Thaillande et de Malaisie (Myriapoda, Diplopoda, Spirostreptida). Bulletin du Muséum national d'Histoire naturelle, 4e Sér., 8 Sect. A: 851-865.

Demange J.-M. 1989. Sur quelques Harpagophoridae du Sud-Est asiatique et de l'Inde (Myriapoda, Diplopoda, Spirostreptoidea). Bulletin du Muséum national d'Histoire naturelle, 4 e Sér., 11 Sect. A: 773-781.

Edgar R.C. 2004. MUSCLE: multiple sequence alignment with high accuracy and high throughput. Nucleic Acids Research 32 (5): 1792-97. http://dx.doi.org/10.1093/nar/gkh340

Enghoff H. 2005. The millipedes of Thailand (Diplopoda). Steenstrupia 29 (1): 87-103.

Folmer O., Black M., Hoeh W., Lutz R. \& Vrijenhoek R. 1994. DNA primers for amplification of mitochondrial cytochrome c oxidase subunit I from diverse metazoan invertebrates. Molecular Marine Biology and Biotechnology 3 (5): 294-299.

Gu X., Fu Y.K. \& Li W.H. 1995. Maximum likelihood estimation of the heterogeneity of substitution rate among nucleotide sites. Molecular Biology and Evolution 12 (4): 546-557.

Hebert P.D.N., Ratnasingham S. \& deWaard J.R. 2003. Barcoding animal life: cytochrome c oxidase subunit 1 divergences among closely related species. Proceedings of the Royal Society of London B (Supplement) 270: S96-S99. http://dx.doi.org/10.1098/rsbl.2003.0025

Hillis D. \& Bull J. 1993. An empirical test of bootstrapping as a method for assessing confidence in phylogenetic analysis. Systematic Biology 42 (2): 182-192. http://dx.doi.org/10.1093/sysbio/42.2.182

Hoffman R.L. 1975. Studies on spirostreptoid millipeds. XI. A review of some Indonesian genera of the family Harpagophoridae. Journal of Natural History 9 (2): 121-152. http://dx.doi. org/10.1080/00222937500770101

Jeekel C.A.W. 2006. A bibliographic catalogue of the Oriental Harpagophoridae (Diplopoda, Spirostreptida). Myriapod Memoranda 9: 5-58.

Karsch F. 1881. Neue Juliden des Berliner Museums, als Prodromus einer Juliden-Monographie. Zeitschrift für die gesammten Naturwissenschaften 54: 1-79.

Kessing B., Croom H., Martin A., McIntosh C., McMillan W.O. \& Palumbi S. 1989. The Simple Fool's Guide to PCR. University of Hawaii, Department of Zoology, Honolulu, Hawaii: 1-23.

Kumar S. \& Nei M. 2000. Molecular Evolution and Phylogenetics. Oxford University Press, New York.

Miller M.A., Pfeiffer W. \& Schwartz T. 2010. Creating the CIPRES Science Gateway for inference of large phylogenetic trees. Proceedings of the Gateway Computing Environments Workshop (GCE), 14 Nov. 2010, New Orleans, LA: 1-8.

Pimvichai P., Enghoff H. \& Panha S. 2009a. A revision of the Thyropygus allevatus group. Part 1: the T. opinatus subgroup (Diplopoda: Spirostreptida: Harpagophoridae). Zootaxa 2016: 17-50.

Pimvichai P., Enghoff H. \& Panha S. 2009b. A revision of the Thyropygus allevatus group. Part 2: the T. bifurcus subgroup (Diplopoda, Spirostreptida, Harpagophoridae). Zootaxa 2165: 1-15.

Pimvichai P., Enghoff H. \& Panha S. 2011a. A revision of the Thyropygus allevatus group. Part 3: the T. induratus subgroup (Diplopoda: Spirostreptida: Harpagophoridae). Zootaxa 2941: 47-68.

Pimvichai P., Enghoff H. \& Panha S. 2011b. A revision of the Thyropygus allevatus group. Part 4: the T. cuisinieri subgroup (Diplopoda: Spirostreptida: Harpagophoridae). Zootaxa 2980: 37-48.

Pimvichai P., Enghoff H. \& Panha S. 2014. Molecular phylogeny of the Thyropygus allevatus group of giant millipedes and some closely related groups. Molecular Phylogenetics and Evolution 71: 170-183. http://dx.doi.org/10.1016/j.ympev.2013.11.006 
Rambaut A., Suchard M.A., Xie W. \& Drummond A.J. 2014. Tracer v1.6. Available from http://beast. bio.ed.ac.uk/Tracer [accessed 12 Dec. 2015]

Spelda J., Hans S. Reip H.S., Oliveira-Biener U. \& Melzer R.R. 2011. Barcoding Fauna Bavarica: Myriapoda - a contribution to DNA sequence-based identifications of centipedes and millipedes (Chilopoda, Diplopoda). ZooKeys 156: 123-139. http://dx.doi.org/10.3897/zookeys.156.2176

Stamatakis A. 2014. RAxML Version 8: A tool for phylogenetic analysis and post-analysis of large phylogenies. Bioinformatics 30 (9): 1312-1313. http://dx.doi.org/10.1093/bioinformatics/btu033

Tamura K., Stecher G., Peterson D., Filipski A. \& Kumar S. 2013. MEGA6: Molecular Evolutionary Genetics Analysis, version 6.0. Molecular Biology and Evolution 30 (12): 2725-2729. http://dx.doi. org $/ 10.1093 / \mathrm{molbev} / \mathrm{mst} 197$

Xia X. 2013. DAMBE5: A comprehensive software package for data analysis in molecular biology and evolution. Molecular Biology and Evolution 30 (7): 1720-1728. http://dx.doi.org/10.1093/molbev/ $\underline{\text { mst064 }}$

Manuscript received: 14 December 2015

Manuscript accepted: 15 January 2016

Published on: 24 May 2016

Topic editor: Rudy Jocqué

Desk editor: Danny Eibye-Jacobsen

Printed versions of all papers are also deposited in the libraries of the institutes that are members of the EJT consortium: Muséum national d'Histoire naturelle, Paris, France; Botanic Garden Meise, Belgium; Royal Museum for Central Africa, Tervuren, Belgium; Natural History Museum, London, United Kingdom; Royal Belgian Institute of Natural Sciences, Brussels, Belgium; Natural History Museum of Denmark, Copenhagen, Denmark. 


\section{Appendix I}

Estimates of evolutionary divergence between 16S rRNA sequences expressed as p-distance.

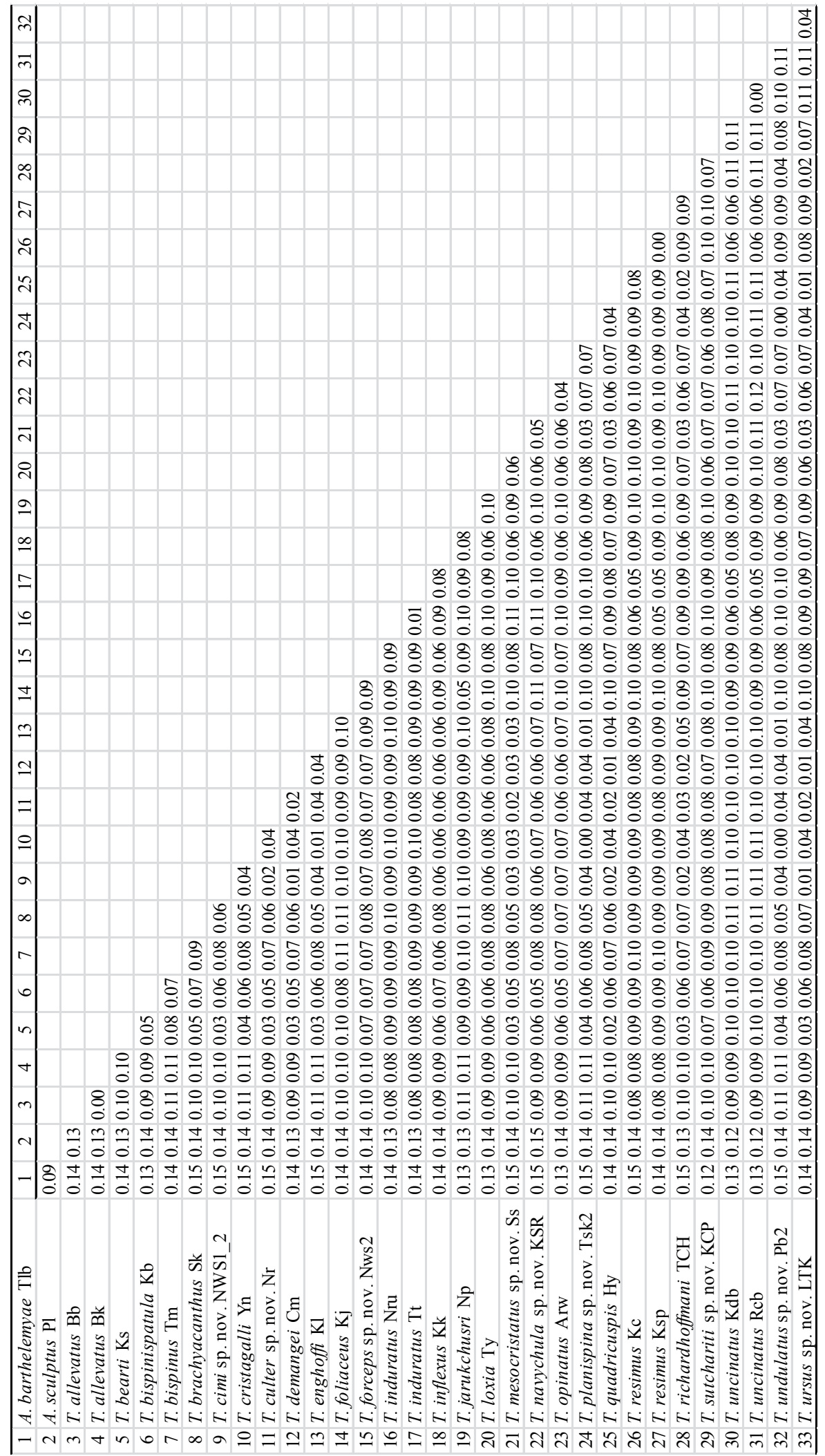




\section{Appendix II}

Phylogenetic relationships of Thyropygus species based on maximum likelihood analysis (ML) and Bayesian Inference (BI) of partial COI gene (660 bp). Numbers at nodes indicate branch support based on bootstrapping $(\mathrm{ML}) /$ posterior probability $(\mathrm{BI})$. Scale bar $=0.07$ substitutions/site. \# indicates branches which received $<50 \%$ ML bootstrap support and $<0.70$ BI posterior probability, - indicates non-supported branches by posterior probability. Abbreviations after species names refer to locality names as shown in Table 1.

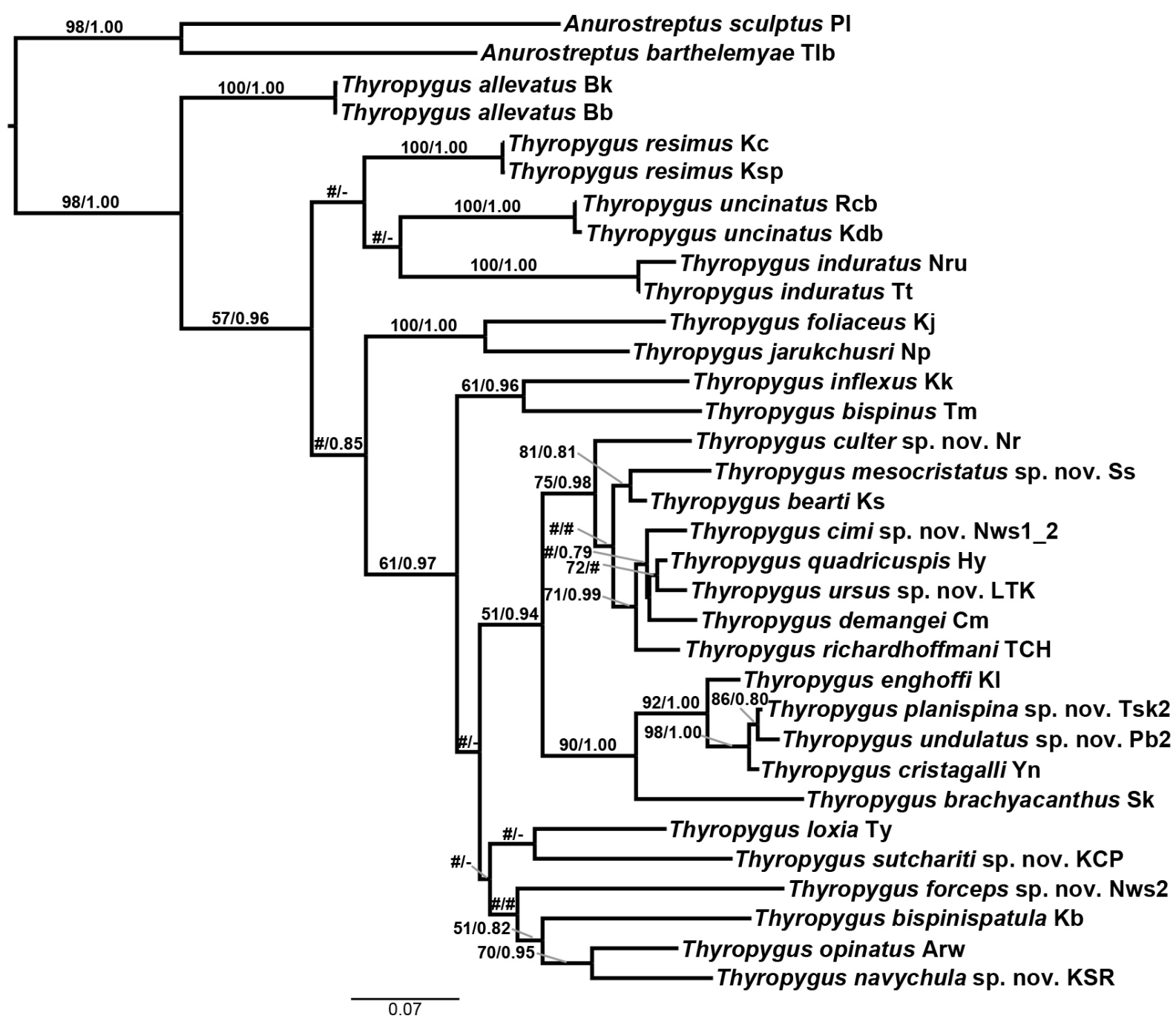




\section{Appendix III}

Phylogenetic relationships of Thyropygus species based on maximum likelihood analysis (ML) and Bayesian Inference (BI) of partial 16S rRNA gene (487 bp). Numbers at nodes indicate branch support based on bootstrapping (ML) / posterior probability (BI). Scale bar $=0.06$ substitutions/site. \# indicates branches which received $<50 \%$ ML bootstrap support and $<0.70$ BI posterior probability, - indicates non-supported branches by posterior probability. Abbreviations after species names refer to locality names as shown in Table 1.

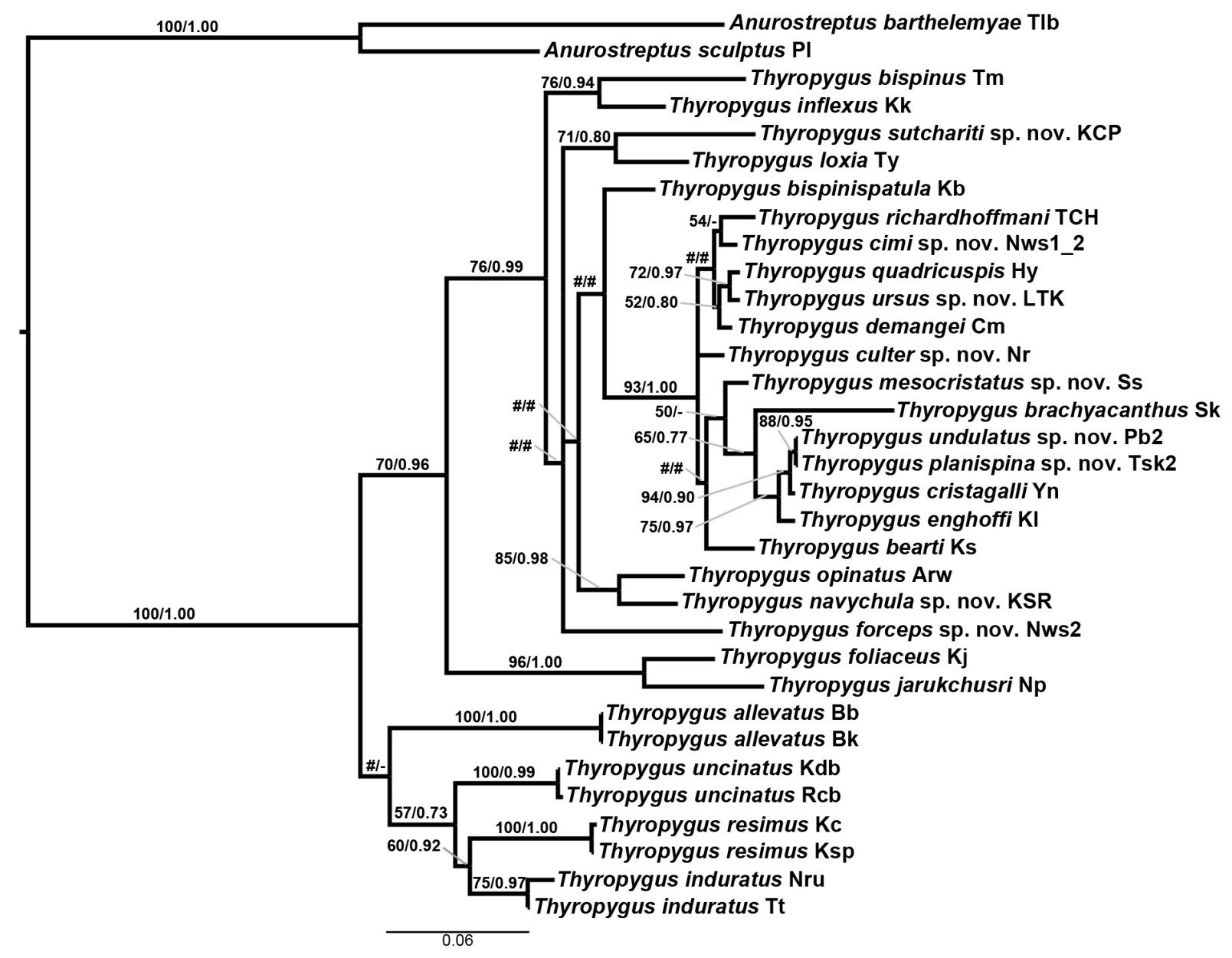

